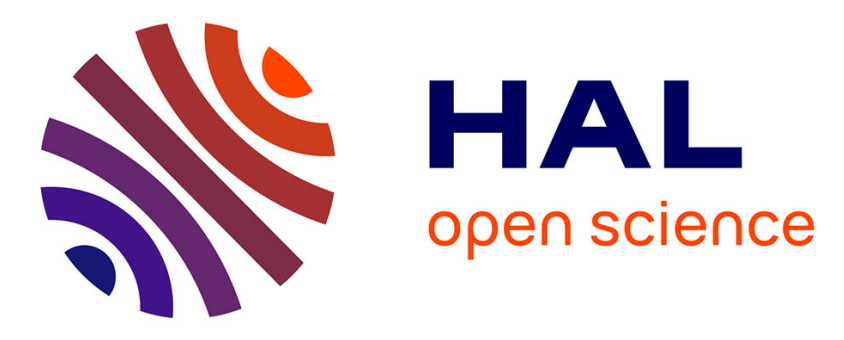

\title{
Mineralogical composition, structure, morphology and geological history of Aram Chaos crater fill on Mars derived from OMEGA Mars Express data
}

M. Massé, Stéphane Le Mouélic, O. Bourgeois, Combe J.Ph., Le Deit L., C. Sotin, Bibring J.P., B. Gondet, Y. Langevin

\section{To cite this version:}

M. Massé, Stéphane Le Mouélic, O. Bourgeois, Combe J.Ph., Le Deit L., et al.. Mineralogical composition, structure, morphology and geological history of Aram Chaos crater fill on Mars derived from OMEGA Mars Express data. Journal of Geophysical Research, 2008, 113, pp.10. 10.1029/2008JE003131 . hal-00488981

\section{HAL Id: hal-00488981 https://hal.science/hal-00488981}

Submitted on 8 Jul 2021

HAL is a multi-disciplinary open access archive for the deposit and dissemination of scientific research documents, whether they are published or not. The documents may come from teaching and research institutions in France or abroad, or from public or private research centers.
L'archive ouverte pluridisciplinaire HAL, est destinée au dépôt et à la diffusion de documents scientifiques de niveau recherche, publiés ou non, émanant des établissements d'enseignement et de recherche français ou étrangers, des laboratoires publics ou privés.

$$
\text { Copyright }
$$




\title{
Mineralogical composition, structure, morphology, and geological history of Aram Chaos crater fill on Mars derived from OMEGA Mars Express data
}

\author{
M. Massé, ${ }^{1}$ S. Le Mouélic, ${ }^{1}$ O. Bourgeois, ${ }^{1}$ J.-P. Combe, ${ }^{2}$ L. Le Deit,${ }^{1}$ C. Sotin, ${ }^{3}$ \\ J.-P. Bibring, ${ }^{4}$ B. Gondet, ${ }^{4}$ and Y. Langevin ${ }^{4}$ \\ Received 27 February 2008; revised 27 May 2008; accepted 29 August 2008; published 9 December 2008.
}

[1] Aram Chaos is a crater $280 \mathrm{~km}$ in diameter centered at $2.5^{\circ} \mathrm{N}, 338.5^{\circ} \mathrm{E}$. It is filled by chaotic terrains overlain by a dome-shaped, layered $900 \mathrm{~m}$ thick formation displaying spectral signatures of ferric oxides on Thermal Emission Spectrometer (TES) and Observatoire pour la Mineralogie, L'Eau, les Glaces et L'Activite (OMEGA) medium spatial resolution data. We describe in detail the mineralogical composition, structure, and morphology of this crater fill using high-resolution data (OMEGA, Mars Orbiter Laser Altimeter, Mars Orbiter Camera, TES, Thermal Emission Imaging System, and HighResolution Imaging Science Experiment). We infer the following formation scenario: the crater was first filled by a geological formation, the composition of which remains unclear because it is covered by dust. Widespread fracturing of this formation led to the development of chaotic terrains. Later, a second layered formation, presently dome shaped, was emplaced unconformably on the chaotic terrains. This younger unit is composed of a bright, poorly consolidated material that contains both monohydrated sulfates and ferric oxides according to OMEGA data. The surface of this formation is partially covered by dust and displays landforms indicating that the bright material has been mobilized by wind during or after its deposition. After its emplacement, this formation has been grooved down to various depths by large eolian erosion corridors. In these corridors, eolian removal of the bright material with a sulfate-rich matrix has left debris fans, sand sheets, and dunes, which display some of the strongest spectral signatures of ferric oxides on Mars. Similar residual deposits enriched in ferric oxides, overlying a layered formation containing both ferric oxides and sulfates, have been observed by the Opportunity rover in Meridiani Planum, suggesting a common formation process.

Citation: Massé, M., S. Le Mouélic, O. Bourgeois, J.-P. Combe, L. Le Deit, C. Sotin, J.-P. Bibring, B. Gondet, and Y. Langevin (2008), Mineralogical composition, structure, morphology, and geological history of Aram Chaos crater fill on Mars derived from OMEGA Mars Express data, J. Geophys. Res., 113, E12006, doi:10.1029/2008JE003131.

\section{Introduction}

[2] The Thermal Emission Spectrometer (TES) thermal infrared spectrometer onboard Mars Global Surveyor provided the first clues about the mineralogical composition of the surface of Mars [Christensen et al., 2001]. This instrument, working with a best spatial resolution of $3 \times$ $3 \mathrm{~km} /$ pixel, revealed that very localized sites (Meridiani Planum, Aram Chaos, and a few small spots in Valles Marineris) display emissivity spectra consistent with the presence of ferric oxide deposits. The Observatoire pour la

\footnotetext{
${ }^{1}$ Laboratoire de Planétologie et Géodynamique, Université de Nantes, UMR6112, CNRS, Nantes, France.

${ }^{2}$ Bear Fight Center, Winthrop, Washington, USA.

${ }^{3}$ Jet Propulsion Laboratory, Pasadena, California, USA.

${ }^{4}$ Institut d'Astrophysique Spatiale, Université Paris XI, Orsay, France.
}

Copyright 2008 by the American Geophysical Union. 0148-0227/08/2008JE003131
Mineralogie, L'Eau, les Glaces et L'Activite (OMEGA) visible and infrared imaging spectrometer onboard Mars Express, inserted into the Martian orbit in December 2003, has since then provided new constraints on the composition of the Martian surface. The spatial resolution of OMEGA ranges from 0.3 to $4 \mathrm{~km} /$ pixel, with a reflectance spectrum from 0.38 to $5.2 \mu \mathrm{m}$ acquired for each pixel. The global analysis of this new data set also showed several spectral signatures of ferric oxides in Meridiani Planum, Aram Chaos, and Valles Marineris [Bargery et al., 2006; Bibring et al., 2007; Le Deit et al., 2008]. Global studies at medium spatial resolution also indicate the presence of sulfates in some of these areas, in association with ferric oxides [Gendrin et al., 2005; Bibring et al., 2007; Sefton-Nash and Catling, 2008].

[3] The detection of ferric oxides and sulfates on Mars is of importance because their formation on Earth occurs under specific physical and chemical conditions, generally involving water [Chevrier and Mathé, 2007]. Consequently, under- 


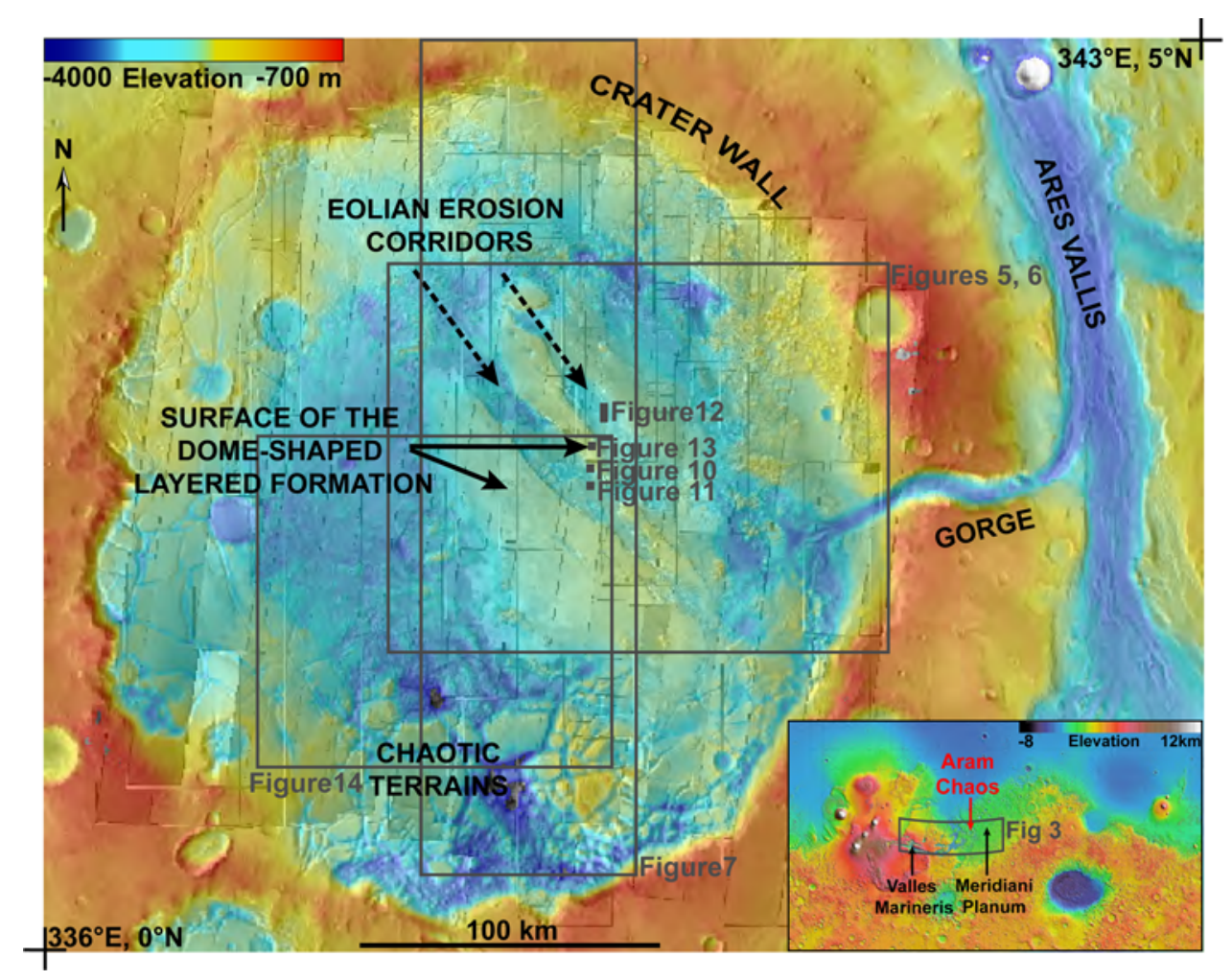

Figure 1. Morphological map of Aram Chaos (superimposition of a MOLA digital elevation model (DEM) on a mosaic of visible THEMIS images). Locations of Figures 5, 6, and 10-14 are indicated by gray boxes. The inset indicates the location of Aram Chaos and of Figure 3 on a MOLA topographic map of Mars.

standing the nature, composition, formation processes and environmental settings of the geological formations containing these minerals on Mars is fundamental to constrain the geological history and the climatic evolution of the planet.

[4] The aim of this study is to describe in detail the mineralogical composition, the structure and the morphology of the Aram Chaos site, using high-resolution data, in order to constrain the geological processes and the history of its formation. In section 2, we briefly describe the geological setting of Aram Chaos and review previous studies of this crater. In section 3, we present the OMEGA data processing methods that were implemented. In section 4 , the results of the mineralogical detection are presented and compared to the morphology deduced from high spatial resolution imagery. This work constrains an interpretation and a discussion of the geological history of Aram Chaos that concludes the article.

\section{Geological Setting}

[5] Aram Chaos is a Martian crater $280 \mathrm{~km}$ in diameter centered at $2.5^{\circ} \mathrm{N}$ and $338.5^{\circ} \mathrm{E}$ (Figure 1). It is connected to the Ares Vallis outflow channel by a $15 \mathrm{~km}$ wide and $2.5 \mathrm{~km}$ deep gorge [Schultz et al., 1982; Kraal et al., 2006], which cuts across the eastern wall of the crater (Figure 1).

[6] Global observations have revealed that this crater is filled by two successive geological sequences [Glotch and Christensen, 2005; Oosthoek et al., 2007; Noe Dobrea et al., 2008]: the older one corresponds to chaotic terrains, well-known here and elsewhere on the Martian surface
[Sharp, 1973; Schultz et al., 1982], with various polygonal fractures and mesas, whereas the younger one corresponds to a layered formation, which is presently dome shaped and is located in the eastern central part of Aram Chaos (Figure 1). Previous mineralogical studies based on TES data, concluded that spectral signatures of ferric oxides, attributed to crystalline gray hematite, are present on a single intermediate layer within this younger sequence [Christensen et al., 2001; Catling and Moore, 2003; Ormö et al., 2004; Tanaka and Skinner, 2004; Glotch and Christensen, 2005; Oosthoek et al., 2007]. OMEGA data at medium spatial resolution revealed that some monohydrated sulfates, possibly kieserite, are also present at lower topographic levels within the dome-shaped formation, close to the ferric oxides unit [Gendrin et al., 2005]. It was therefore suggested that this dome-shaped formation is composed of various layers with different mineralogical compositions [Catling and Moore, 2003; Glotch and Christensen, 2005].

[7] In order to constrain more comprehensively and more precisely the geological processes and the history of this region, we use new high-resolution data sets to analyze the mineralogical composition, the structure and the morphology of Aram Chaos.

\section{Data and Methods}

\subsection{Mineralogical Composition}

\subsubsection{Data Reduction}

[8] We investigated in detail the mineralogical composition of Aram Chaos using data acquired by the OMEGA 


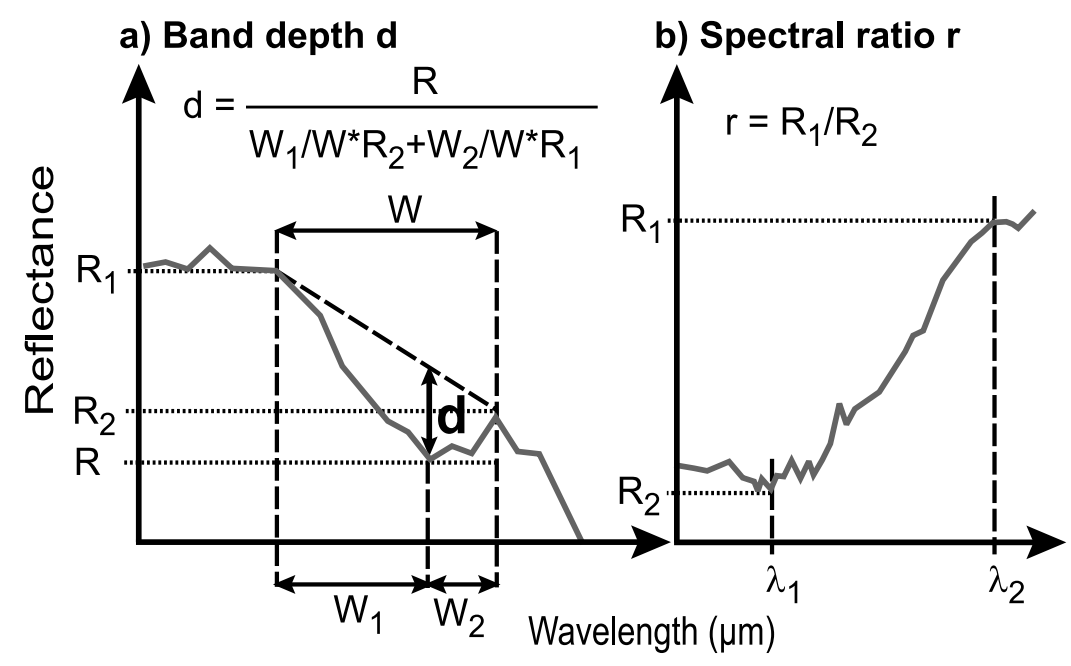

Figure 2. Spectral criteria used in this study. (a) Absorption band depth, where $W$ is the width of absorption band, $W_{1}$ is the width between left shoulder and center of band, $W_{2}$ is the width between right shoulder and center of band, $R$ is the reflectance at center of band, $R_{1}$ is the reflectance on right shoulder, and $R_{2}$ is the reflectance on left shoulder. To improve the signal/noise ratio, $R, R_{1}$, and $R_{2}$ are computed as the averages of one to four adjacent OMEGA channels. (b) Spectral ratio, where $R_{1}$ is the reflectance at wavelength $\lambda_{1}$ and $R_{2}$ is the reflectance at wavelength $\lambda_{2}$.

imaging spectrometer [Bibring et al., 2004]. This instrument onboard Mars Express has completed a near global coverage of Mars since December 2003. It acquires hyperspectral images at a spatial resolution ranging from $300 \mathrm{~m}$ to $4 \mathrm{~km}$ per pixel. A spectrum is acquired in 352 spectral channels from 0.38 to $5.2 \mu \mathrm{m}$ for each pixel of an image, thus producing data cubes. OMEGA is composed of three detectors: VNIR (Visible Near Infrared) between 0.38 and $1.05 \mu \mathrm{m}$, SWIR (Short-Wavelength Infrared) between 0.93 and $2.73 \mu \mathrm{m}$, and LWIR (Long-Wavelength Infrared) between 2.55 and $5.2 \mu \mathrm{m}$. Diagnostic spectral features in the visible and near infrared domains provide information on the mineralogical composition of the surface and on the atmosphere of the planet.

[9] We restricted our analysis to the spectral domain comprised between 0.4 and $2.6 \mu \mathrm{m}$. In this wavelength range, the solar reflected light dominates the spectrum, and the thermal emission is negligible [Gendrin et al., 2005]. We made a systematic study of all the data cubes covering Aram Chaos from the first orbit up to orbit 4200. Eight data cubes were acquired under poor atmospheric conditions (water ice clouds, atmospheric dust), and were therefore not included in the final mosaic. We used the following nine data cubes: scenes 0401_3, 0353_2, and 0434_3, which provide a nearly complete coverage of the crater at
[10] OMEGA spectra are acquired remotely through the atmosphere. In order to extract the spectral contribution of the surface only, the atmospheric spectral contribution is removed by using an empirical atmospheric transmission law derived from the ratio between two spectra acquired at the summit and the base of the Olympus Mons edifice, and scaled to the depth of the $\mathrm{CO}_{2}$ band [Langevin et al., 2005]. 3.1.2. Extraction of Mineralogical Information

[11] The first data analysis method we use is based on five spectral criteria. These are either band depths or spectral ratios (Figure 2). They are computed for each pixel of an OMEGA cube, and maps of each spectral criterion are then produced (Figure 5, which will be discussed later). This method allows us to identify specific mineralogical compositions and provides the spatial distribution of the corresponding minerals.

[12] Absorption bands centered at 1.46 and $1.9 \mu \mathrm{m}$ are characteristic of hydrated minerals such as hydrated oxides, polyhydrated sulfates and clays. We use two spectral criteria, $d_{1.46}$ and $d_{1.93}$, defined as follows, to measure the depth of these bands:

$$
d_{1.46}=1-\frac{R(1.46)}{(0.5) R(1.59)+(0.5) R(1.33)}
$$

$$
d_{1.93}=1-\frac{\left(\frac{R(1.92)+R(1.94)}{2}\right)}{0.12\left(\frac{R(1.99)+R(2.01)+R(2.03)}{3}\right)+0.48\left(\frac{R(1.84)+R(1.86)}{2}\right)} .
$$

$1.5-6 \mathrm{~km} / \mathrm{pixel}$, and scenes 1326_1, 1337_1, 1337_2, 2240_3, 2262_3, and 2284_3 which have a spatial resolu-

[13] $(R(x)$ is the value of reflectance corresponding to the wavelength at $x \mu \mathrm{m}$.) To characterize the typical increase of tion of $0.6-1 \mathrm{~km} /$ pixel. 
reflectance between $0.92 \mu \mathrm{m}$ and $1.3 \mu \mathrm{m}$, which is characteristic of ferric oxides, we use the following $r_{1}$ criterion:

$$
r_{1}=\frac{R(1.30)}{R(0.92)} .
$$

[14] An absorption band centered at $2.1 \mu \mathrm{m}$ is characteristic of monohydrated sulfates [Gendrin et al., 2005]. We measure the depth of this band with a criterion $d_{2.1}$ defined as follows:

$$
d_{2.1}=\frac{\left(\frac{R(2.08)+R(2.09)+R(2.11)+R(2.12)}{4}\right)}{0.46\left(\frac{R(2.19)+R(2.21)}{2}\right)+0.53\left(\frac{R(2.01)+R(2.03)}{2}\right)} .
$$

[15] A decrease of reflectance between 2.2 and $2.4 \mu \mathrm{m}$ is characteristic of some ferric oxides or polyhydrated and monohydrated sulfates. We use the following $r_{2}$ criterion to characterize this spectral feature:

$$
r_{2}=\frac{R(2.22)}{R(2.41)} .
$$

[16] Natural geological surfaces are generally composed of mixtures of minerals. Therefore a spectrum of a planetary surface, acquired remotely by an orbiter, is a complex combination of the spectra of all mineralogical components present in the field of view of each pixel. To estimate the mineralogical composition of the surface, the various spectral signatures corresponding to the different minerals must be extracted from the overall spectrum measured in that pixel. To perform this extraction, we use a second method called Multiple-End-Member Linear Spectral Unmixing Model (MELSUM) and described by Combe et al. [2008]. In this model, we automatically find for each pixel the best linear combination of a suite of laboratory spectra of pure minerals which reproduces the OMEGA data, using a least squares adjustment. This physically corresponds to areal mixtures, where the various mineralogical components of a given pixel are arranged in spatially distinct patterns. We use as input a library containing spectra representative of the main families of rock-forming minerals described by Crowley et al. [2003], Combe et al. [2008], and Le Deit et al. [2008]. The MELSUM includes several improvements compared to other linear unmixing algorithms available in the literature [Adams et al., 1986, 1993; Boardman, 1989; Ramsey and Christensen, 1998; Roberts et al., 1998]. In particular, we add three synthetic components (a flat spectrum and two pure positive and negative slopes) in the input mineral library in order to take into account the shading, grain size and aerosol scattering effects. We also constrain the model by exploring the full space of combinations of 3 mineralogical components, and keeping the solution providing the best root mean square (RMS) fit [Combe et al., 2008].

[17] The algorithm multiplies each spectrum of the library by a mixing coefficient. This coefficient is sensitive to the spectral expression of the given component in the total observed spectrum. It is therefore not an absolute mineral proportion in the rock. The detection limits still have to be determined; low-mixing coefficients should therefore be taken with care. Maps of the mixing coefficients computed by the MELSUM are produced for each mineral of the library. The most interesting components are reproduced in Figure 6, which will be discussed later.

[18] We systematically crosscheck the results of both the linear unmixing and the spectral criteria methods in order to gain confidence in the mineral detections. In addition, a visual inspection of the spectra is carried out in order to confirm the interpretations.

\subsection{Morphology and Structure}

[19] We investigate the morphology and the structure of Aram Chaos with complementary data sets which provide different kinds of information.

[20] Topographic information is provided by the Mars Orbiter Laser Altimeter (MOLA) global digital terrain model (Figure 1), with a relative vertical accuracy of $1 \mathrm{~m}$ and an average spatial resolution of $300 \mathrm{~m} /$ pixel [Smith et al., 2001].

[21] Geomorphological and structural information is provided by (1) daytime visible images of the Thermal Emission Imaging System (THEMIS) with a resolution of $18 \mathrm{~m} / \mathrm{pixel}$ [Christensen et al., 2004a], (2) images of the Mars Observer Camera (MOC) with a resolution up to $1.4 \mathrm{~m} /$ pixel [Malin et al., 1992], and (3) images of the High-Resolution Imaging Science Experiment (HiRISE) with a resolution up to $30 \mathrm{~cm} /$ pixel for a field of view of 40000 to 20000 pixels [McEwen et al., 2007].

[22] Textural and compositional information on surface materials is provided by (1) nighttime infrared THEMIS images with a resolution of $100 \mathrm{~m} / \mathrm{pixel}$ [Christensen et al., 2004a; Fergason et al., 2006] and (2) Thermal Emission Spectrometer (TES) images with a best resolution of $3 \times$ $3 \mathrm{~km} /$ pixel [Mellon et al., 2000; Putzig and Mellon, 2007]. These data provide temperature estimates of the Martian surface, which are used to derive thermal inertia values (i.e., the resistance to change in temperature of the upper few centimeters of the surface [Fergason et al., 2006]). Nighttime temperature and thermal inertia increases with increasing induration and/or granulometry of the surface materials [Mellon et al., 2000]. Hence these images are helpful to identify and separate different geological formations on the basis of their texture and composition.

[23] All these images were integrated with the mineralogical maps in a geographic information system using the Mars 2000 geographic coordinate system available in ArcGIS ${ }^{\mathbb{B}}$. From this combination of topographic, structural, geomorphological, textural and mineralogical data, we drew an interpretative geological map of Aram Chaos. The tridimensional consistency of our interpretation was checked by drawing a series of topographically constrained geological cross sections.

\section{Results}

\subsection{Global Map of Ferric Oxides}

[24] We performed a systematic survey of ferric oxide signatures on Mars by applying the spectral linear unmixing model described in section 3.1.2 to a global set of OMEGA data. Figure 3 shows a subset of the ferric oxide component derived from this analysis [Le Mouélic et al., 2006]. 


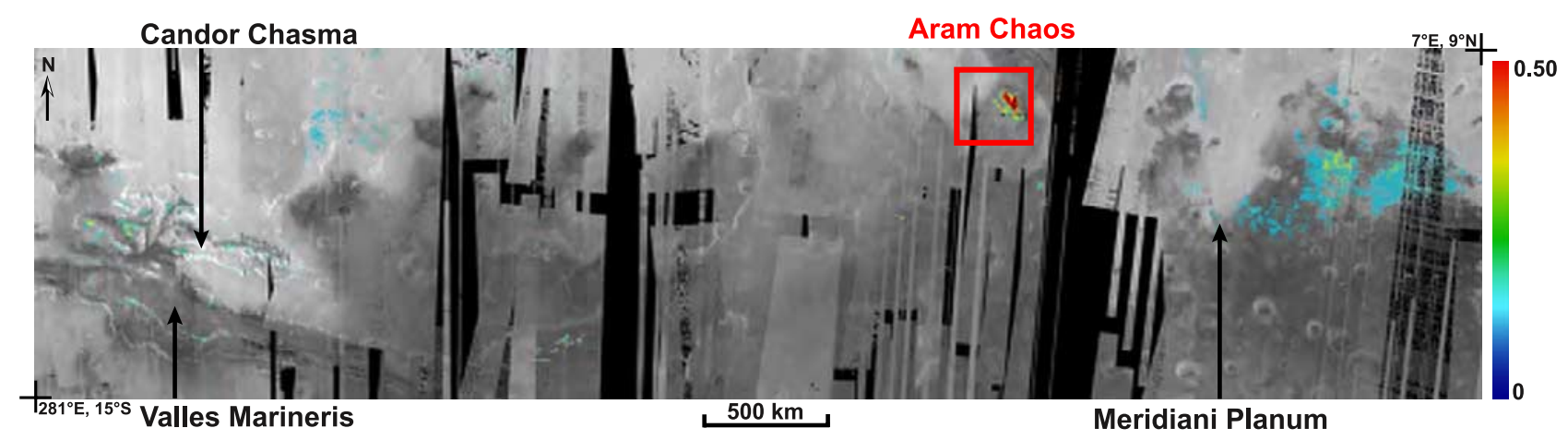

Figure 3. Map of the ferric oxide mixing coefficient derived from the MELSUM (described in section 3.1.1). This mixing coefficient corresponds to the spectral contribution of ferric oxides to the overall OMEGA spectrum and is shown by colors varying from blue to red. The location of this map is indicated by a gray box in Figure 1.

Signatures of ferric oxides appear in Meridiani Planum, Valles Marineris and Aram Chaos. The strongest signatures are located in Aram Chaos, with a mixing coefficient four times as high as the one observed on the mean bright dust in the northern plains. This is in good agreement with the study of Bibring et al. [2007]. Figure 4 shows a series of representative spectra extracted from the mosaic displayed in Figure 3. The spectrum of Aram Chaos displays the strongest increase of reflectance between 0.9 and $1.3 \mu \mathrm{m}$, which is very characteristic of ferric oxides. It shows that Aram Chaos is a key site to understand the formation of these minerals on Mars.

\subsection{Mineralogical Composition}

[25] Figures 5 and 6 show the values of the spectral criteria and of the relevant linear unmixing coefficients derived from the analysis described in part 2.1.2. Using these sets of results, we identified four spectral units (SU), which display distinct spectral characteristics. The spectra of these four units are given in Figure 7. The first three units are located on the dome-shaped, layered formation. The fourth one is located on the chaotic terrains.

\subsubsection{Spectral Unit 1}

[26] Spectral unit 1 (SU1) displays a deep absorption band centered at $0.9 \mu \mathrm{m}$, a significant increase of reflectance between 0.9 and $1.3 \mu \mathrm{m}$, a shallow broad absorption band centered at $1.46 \mu \mathrm{m}$, a deep broad absorption band centered at $1.93 \mu \mathrm{m}$ and a decrease of reflectance between 2.2 and $2.4 \mu \mathrm{m}$ (Figure $7 \mathrm{a}$ ).

[27] The increase of reflectance between 0.9 and $1.3 \mu \mathrm{m}$ can be attributed to three groups of minerals: olivines, pyroxenes and ferric oxides. However, pyroxenes display additional absorption bands centered at $1.88 \mu \mathrm{m}$ for orthopyroxenes, and at $2.15 \mu \mathrm{m}$ for clinopyroxenes. These bands are not observed on the spectra of SU1. The increase of reflectance for olivine is generally distributed across a wider range of wavelengths and is centered at $1.05 \mu \mathrm{m}$. Therefore, only ferric oxides are consistent with the observed spectra. Among the whole family of ferric oxides, only hematite and goethite display a sufficient increase of reflectance to fit the spectra of SU1, as shown in Figure 8. The linear unmixing model favors the goethite end-member, as shown in Figure 6a. Its distribution (Figure 6a) is spatially fully consistent with the spatial distribution of terrains displaying an increase of reflectance between 0.9 and $1.3 \mu \mathrm{m}$ (spectral parameter $r_{1}$, Figure 5a). This is not the case for the hematite end-member (Figure 6d). However, hematite cannot be firmly excluded because spectra of hematite and goethite do not differ markedly: both minerals display a deep absorption band centered at $0.9 \mu \mathrm{m}$, a significant increase of reflectance between 0.9 and $1.3 \mu \mathrm{m}$, and a decrease of reflectance between 2.2 and $2.4 \mu \mathrm{m}$. Hematite generally displays a narrower absorption band centered at a slightly shorter wave-

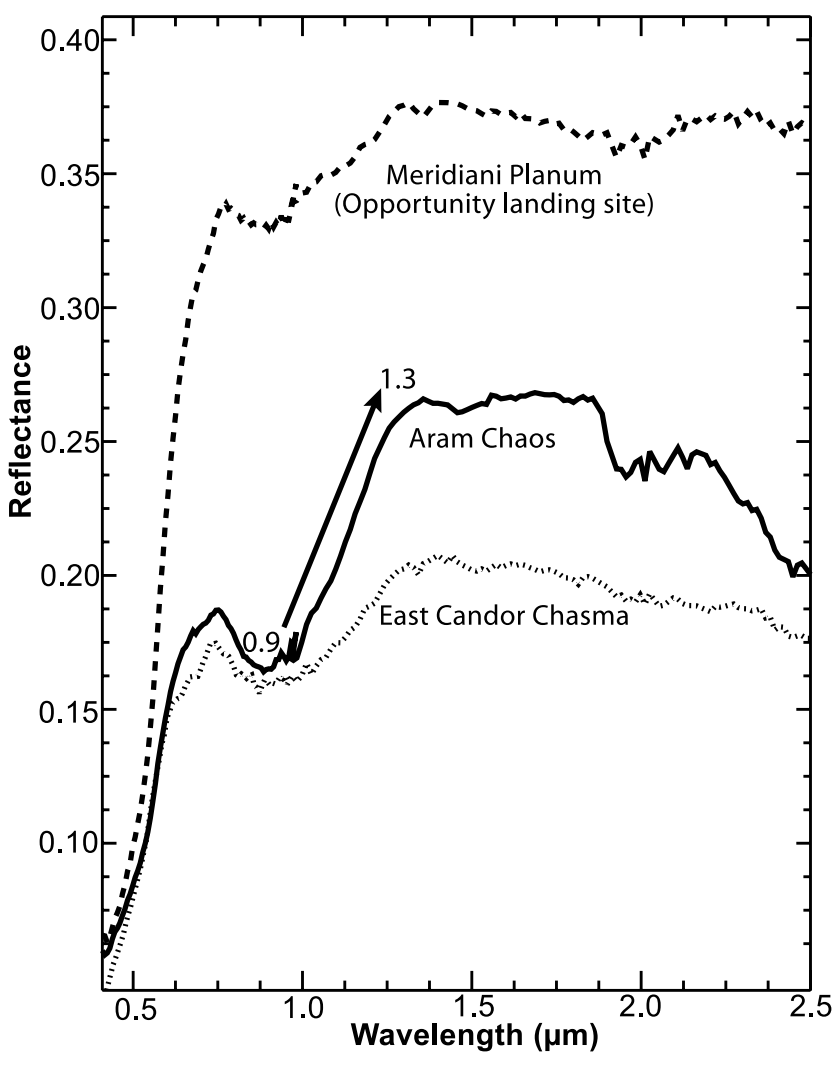

Figure 4. Comparison between representative OMEGA spectra in Aram Chaos, Candor Chasma, and Meridiani Planum (Opportunity landing site). The increase of reflectance between 0.9 and $1.3 \mu \mathrm{m}$, which is typical of ferric oxides, is particularly strong in Aram Chaos. 

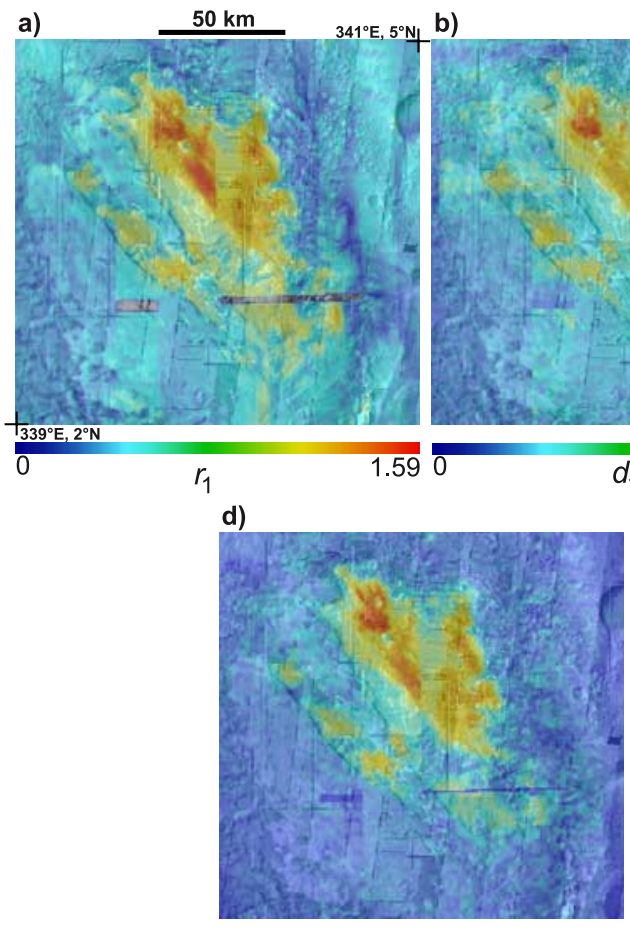

$r_{2}$

1.170 b)

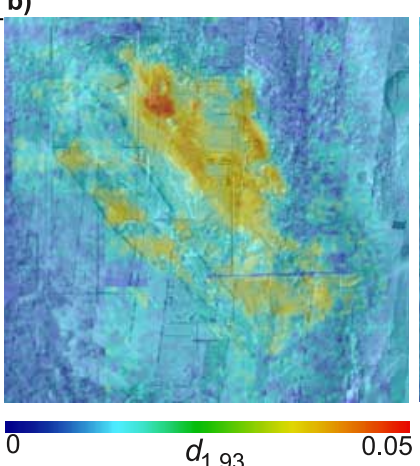

e) c)

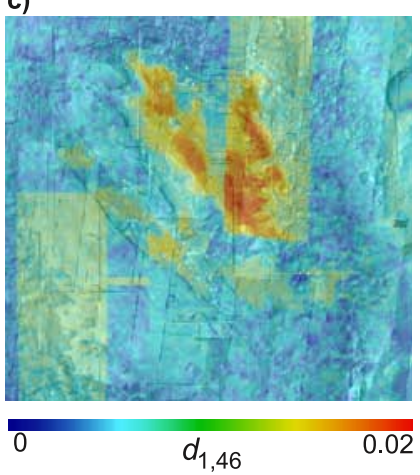

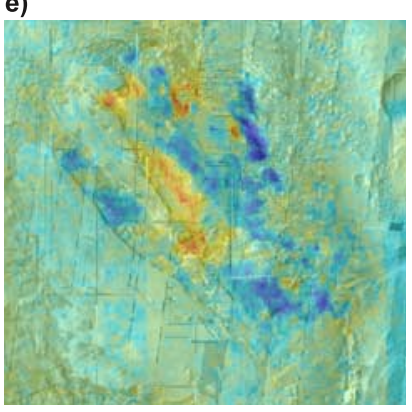

$d_{2,1}$

0.04

Figure 5. Maps of spectral criteria superimposed on a mosaic of visible THEMIS images (location indicated by a gray box in Figure 1) for (a) $r_{1}$, (b) $d_{1.93}$, (c) $d_{1.46}$, (d) $r_{2}$, and (e) $d_{2.1}$.
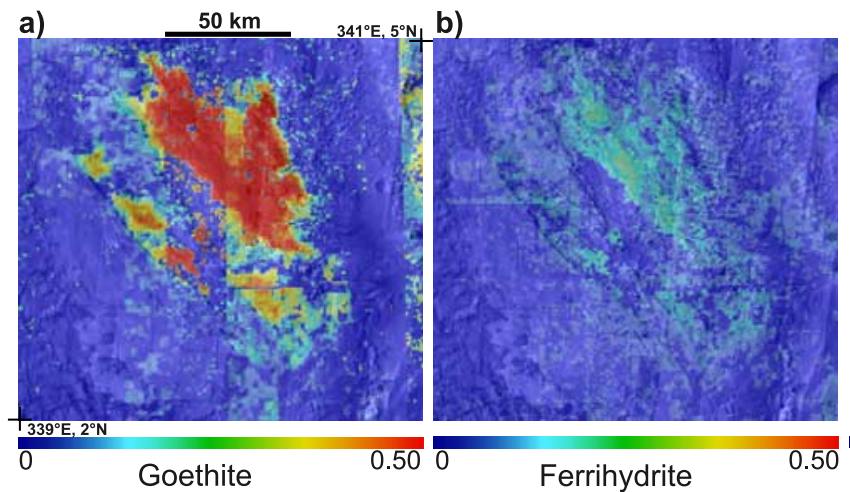

c)
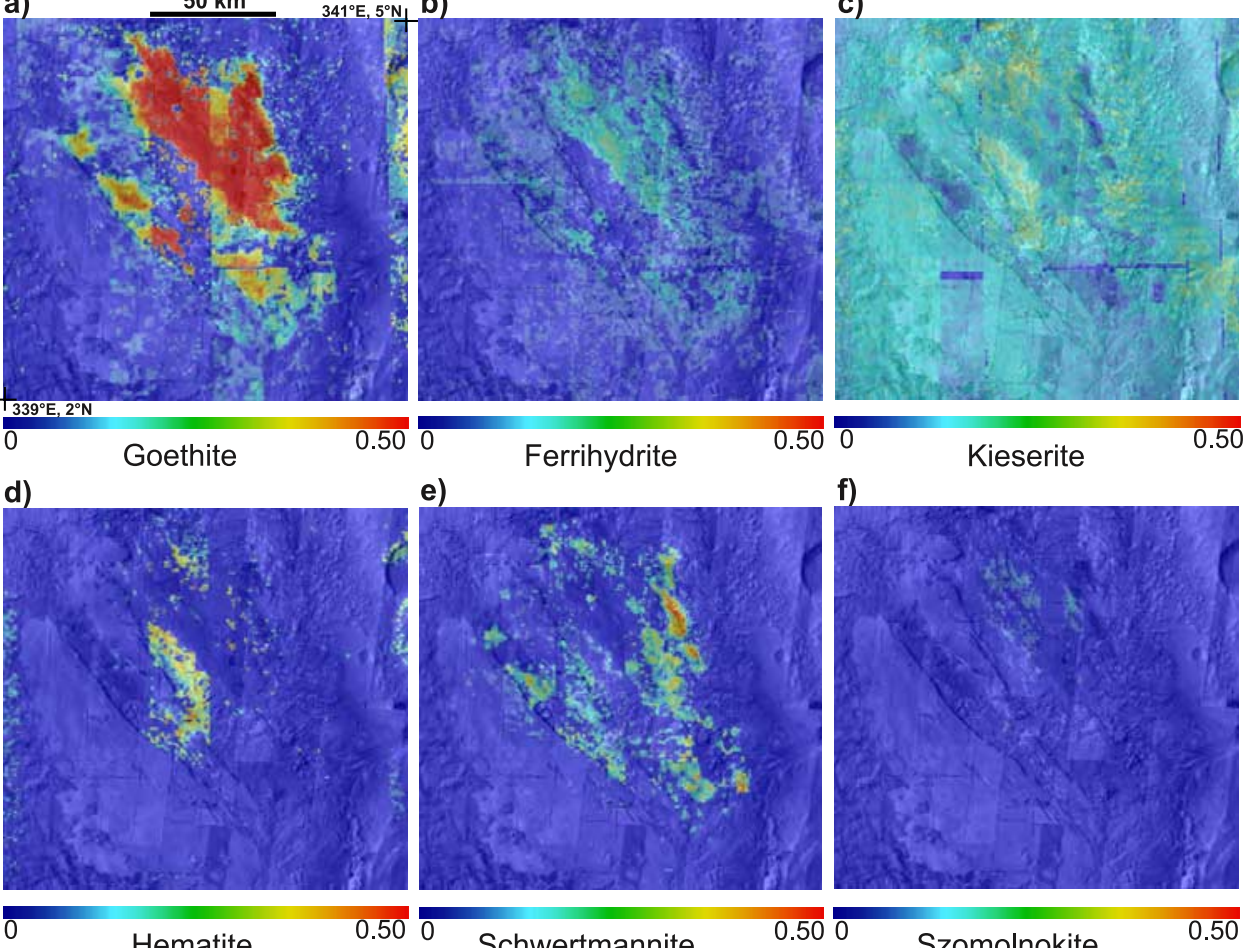

Hematite

Schwertmannite

Szomolnokite

0.50

Figure 6. Maps of the linear unmixing end-member coefficients derived from the MELSUM [Combe et al., 2008], superimposed on a mosaic of visible THEMIS images (location indicated by a gray box in Figure 1) for (a) goethite, (b) ferrihydrite, (c) kieserite, (d) hematite, (e) schwertmannite, and (f) szomolnokite. 


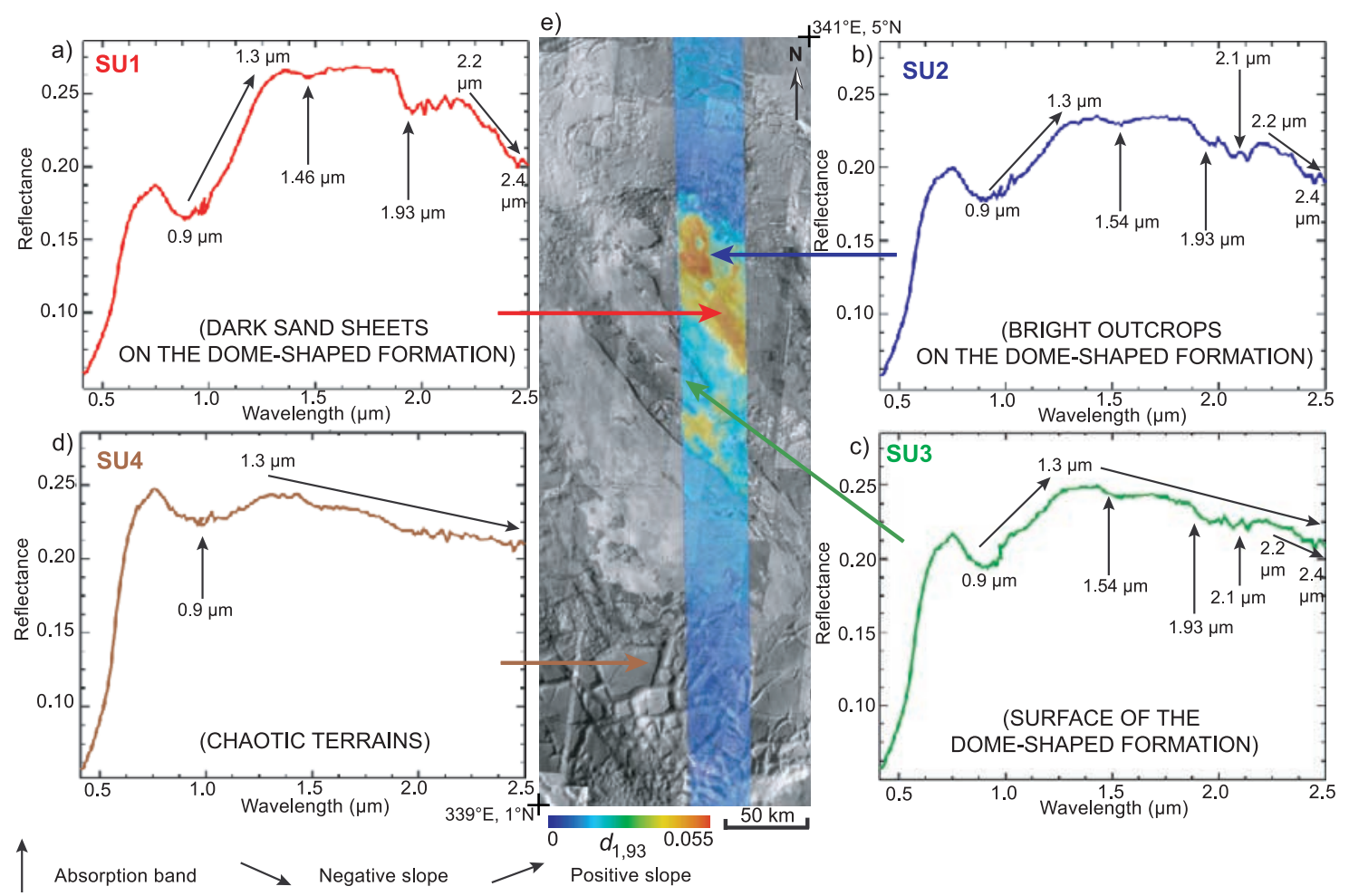

Figure 7. Spectral variability of Aram Chaos. (a-d) Representative spectra of each spectral unit and (e) $d_{1.93}$ spectral criterion computed from scene 2262_3, superimposed on a black and white mosaic of visible THEMIS images (location indicated by a gray box on Figure 1).

length $(0.87 \mu \mathrm{m})$ than goethite $(0.92 \mu \mathrm{m})$, but coarse-grained hematite has a broader absorption band, approaching the position and width of fine-grained goethite [Rencz, 1999]. It should be noted that in the mid infrared, using TES spectra acquired on Aram Chaos, Sinus Meridiani and Candor Chasma, Christensen et al. [2001] conclude that hematite provides the best match for two absorption bands at 300 and $450 \mathrm{~cm}^{-1}$.

[28] Absorption bands centered at $1.46 \mu \mathrm{m}$ and $1.93 \mu \mathrm{m}$ are typical of hydrated minerals. The shape of these bands can correspond to several minerals, with a ferric sulfate (schwertmannite) and an oxyhydroxide (ferrihydrite) being very good candidates (Figure 8). The spatial distribution of terrains displaying these bands (spectral criteria $d_{1.46}$ and $d_{1.93}$, Figures $5 \mathrm{~b}$ and $5 \mathrm{c}$ ) is similar to the spatial distribution of terrains displaying an increase of reflectance between 0.9 and $1.3 \mu \mathrm{m}$ (spectral criteria $r_{1}$, Figure 5a). This indicates either that a hydrated mineral is systematically associated with ferric oxides in SU1, or that SU1 is composed of hydrated ferric oxides. Laboratory spectra analysis reveals that these two absorption bands have similar positions but different shapes for different hydrated minerals. On the basis of this difference in shape, the spectral linear unmixing model selects hydrated ferric oxides to reproduce the observed absorption bands and rejects other families of hydrated minerals. Indeed, the maps of mixing coefficients obtained by our linear unmixing algorithm favor a mixture of goethite and ferrihydrite (Figures 6a and 6b). It is interesting to note that this mixture, identified from spectral criteria only, is a geologically plausible association [Chevrier et al., 2006].

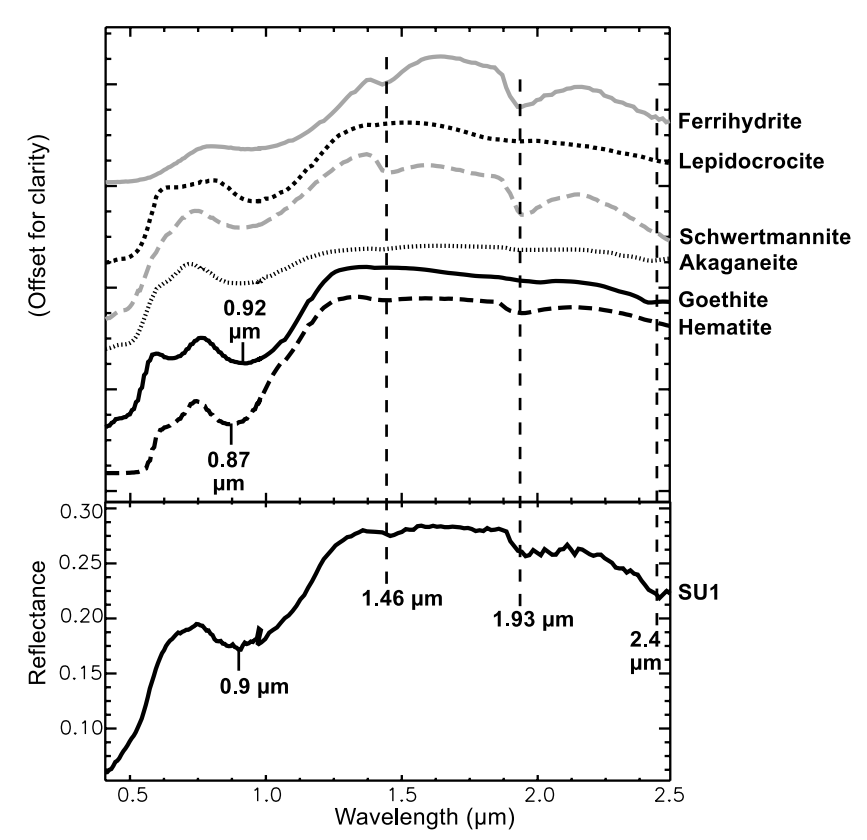

Figure 8. Comparison between an OMEGA spectrum representative of SU1 and laboratory spectra of various ferric oxides [Crowley et al., 2003; Combe et al., 2008; Le Deit et al., 2008] for ferrihydrite $\left(\mathrm{Fe}^{3+}{ }_{2} \mathrm{O}_{3} 0.5\left(\mathrm{H}_{2} \mathrm{O}\right)\right)$, lepidocrocite $\left(\mathrm{Fe}^{3+} \mathrm{O}(\mathrm{OH})\right)$, schwertmannite $\left(\mathrm{Fe}^{3+}{ }_{16} \mathrm{O}_{16}(\mathrm{OH})_{12}\left(\mathrm{SO}_{4}\right)_{2}\right)$, akaganeite $\left(\mathrm{Fe}^{3+}{ }_{7.6} \mathrm{Ni}_{0.4} \mathrm{O}_{6.4}(\mathrm{OH})_{9.7} \mathrm{Cl}_{1.3}\right)$, goethite $\left(\mathrm{Fe}^{3+} \mathrm{O}(\mathrm{OH})\right.$ ), and hematite $\left(\mathrm{Fe}^{3+}{ }_{2} \mathrm{O}_{3}\right)$. 


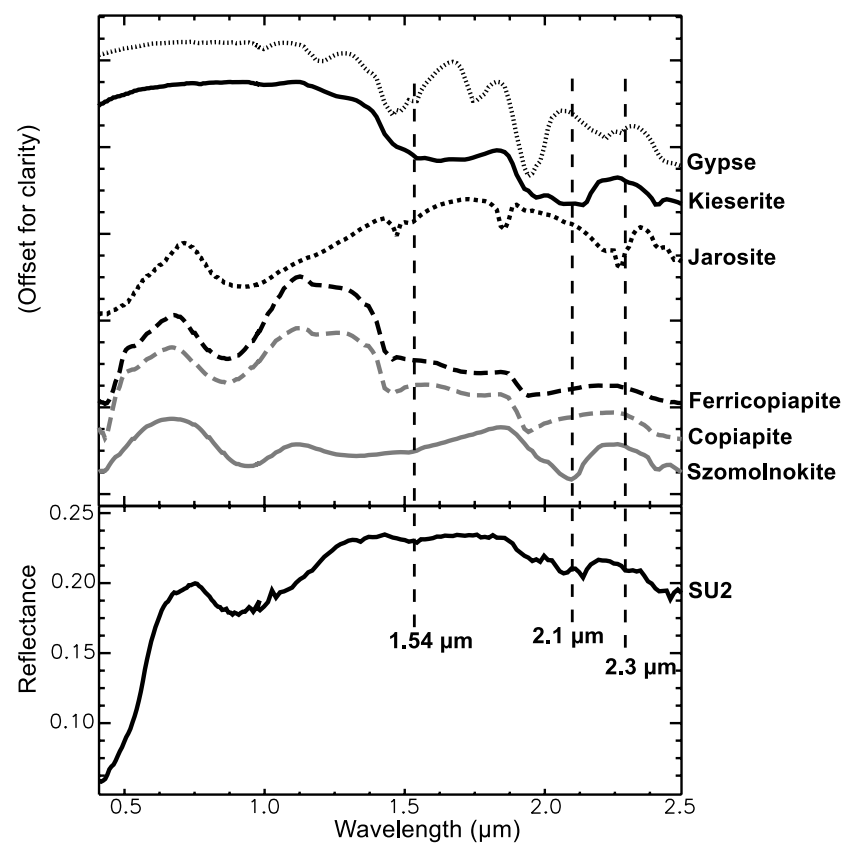

Figure 9. Comparison between an OMEGA spectrum representative of SU2 and laboratory spectra of various sulfates [Crowley et al., 2003; Combe et al., 2008; Le Deit et al., 2008] for gypsum $\left(\mathrm{Ca}\left(\mathrm{SO}_{4}\right) 2\left(\mathrm{H}_{2} \mathrm{O}\right)\right)$, kieserite $\left(\mathrm{Mg}\left(\mathrm{SO}_{4}\right)\right.$ $\left.\left(\mathrm{H}_{2} \mathrm{O}\right)\right)$, jarosite $\left(\mathrm{KFe}_{3}^{3+}\left(\mathrm{SO}_{4}\right)_{2}(\mathrm{OH})_{6}\right)$, ferricopiapite $\left(\mathrm{Fe}^{3+}{ }_{0.6-}\right.$ $\left.\mathrm{Fe}^{3+}{ }_{4}\left(\mathrm{SO}_{4}\right)_{6}(\mathrm{OH})_{2} 20\left(\mathrm{H}_{2} \mathrm{O}\right)\right)$, copiapite $\left(\mathrm{Fe}^{2+} \mathrm{Fe}^{3+}{ }_{4}\right.$ $\left.\left(\mathrm{SO}_{4}\right)_{6}(\mathrm{OH})_{2} 20\left(\mathrm{H}_{2} \mathrm{O}\right)\right)$, and szomolnokite $\left(\mathrm{Fe}^{2+}\left(\mathrm{SO}_{4}\right)\left(\mathrm{H}_{2} \mathrm{O}\right)\right)$.

[29] The decrease of reflectance between 2.2 and $2.4 \mu \mathrm{m}$ is most likely due to the $\mathrm{OH}$ vibrational feature and is consistent with the presence of goethite, ferrihydrite and schwertmannite (Figure 8). Again, the spatial location of terrains displaying this spectral feature (spectral criterion $r_{2}$, Figure 5d), is similar to the spatial location of terrains displaying an increase of reflectance between 0.9 and $1.3 \mu \mathrm{m}$ (spectral criterion $r_{1}$, Figure 5a) and absorption bands at $1.46 \mu \mathrm{m}$ and $1.92 \mu \mathrm{m}$ (spectral criteria $d_{1.46}$ and $d_{1.93}$, Figures $5 \mathrm{~b}$ and $5 \mathrm{c}$ ).

[30] In conclusion, SU1 displays spectral features that are consistent with a mixture of hematite and/or goethite and ferrihydrite and/or schwertmannite. The maps of spectral criteria diagnostic of this unit are consistent with each other and are spatially coherent: terrains displaying these spectral characteristics are arranged in patches that are consistent with morphological boundaries (Figures $5 \mathrm{a}-5 \mathrm{~d}$ ). The spatial location of this unit is consistent also with the distribution of ferric oxides determined from TES data [Christensen et al., 2001; Glotch and Christensen, 2005].

\subsubsection{Spectral Unit 2}

[31] Spectral unit 2 (SU2) displays similar spectral characteristics as SU1, but with an additional band centered at $2.1 \mu \mathrm{m}$ (Figure 7b). This absorption band is typical of monohydrated sulfates [Gendrin et al., 2005]. Laboratory spectra of monohydrated sulfates, which are reproduced in Figure 9, show that szomolnokite (a Fe-sulfate) and kieserite (a Mg- sulfate) are good candidates.

[32] The distribution of terrains displaying this additional band (spectral criterion $d_{2.1}$, Figure 5e) is spatially coherent: these terrains form patches with geologically plausible contours. They are located close to SU1. The mixing coefficients obtained with the linear spectral unmixing algorithm show a coherent map for the kieserite endmember (Figure 6c), and to a lesser extent for szomolnokite (Figure 6f). The map of mixing coefficients obtained for kieserite is consistent with the map of the spectral criterion $d_{2.1}$ (Figure 5e).

[33] The spectral linear unmixing model favors a mixing with a small component of goethite or hematite to explain the increase of reflectance between 0.9 and $1.3 \mu \mathrm{m}$ for SU2, as for SU1.

[34] The spectra of SU2 display absorption bands at 1.92 and $2.4 \mu \mathrm{m}$, as those of SU1. However, the $1.46 \mu \mathrm{m}$ absorption band of SU1 is shifted to $1.54 \mu \mathrm{m}$ on SU2 (Figure 7, SU2). The presence in SU2 of kieserite (which has an absorption band at $1.62 \mu \mathrm{m}$, Figure 9) in addition to ferrihydrite (which has an absorption band at $1.46 \mu \mathrm{m}$, Figure 8) possibly explains the shift of this band to an intermediate position at $1.54 \mu \mathrm{m}$. The spectral linear unmixing model confirms this hypothesis: it reproduces the spectra of SU2 by a mixture of ferric oxides (ferrihydrite and goethite or hematite) and monohydrated sulfates (kieserite). The $2.4 \mu \mathrm{m}$ absorption band is consistent with hematite, goethite and kieserite (Figures 8 and 9).

[35] In conclusion, SU2 forms a spatially coherent unit. Its spectral characteristics are consistent with a mixture of ferric oxides and sulfates (probably kieserite or szomolnokite).

\subsubsection{Spectral Unit 3}

[36] Spectral unit 3 (SU3) displays the same absorption bands as SU2. However, these bands are always shallower than on SU2 (Figure 7d), and their depths vary from one pixel to another. This spectral feature is typical of the presence of dust on the surface: the size of dust grains is so fine that the signal received by the instrument is dominated by surface diffusion, which produces shallower absorption bands [Combe et al., 2008]. The variation of the absorption band depth from one pixel to another may be attributed to lateral variations in the dust coverage. Therefore, we interpret SU3 as regions where a unit similar to SU2 is partially covered by dust.

\subsubsection{Spectral Unit 4}

[37] Spectra of unit 4 (SU4) are nearly flat and display a negative slope starting at $1.3 \mu \mathrm{m}$ (Figure 7c). These spectra are characteristic on Mars of completely dusty areas [Le Mouélic et al., 2006].

\subsection{Location, Morphology, and Texture of Spectral Units}

[38] From the spectral analysis described above, we identified four units, with different mineralogical compositions: SU1 is dominated by ferric oxides, SU2 is consistent with a mixture of ferric oxides and sulfates, SU3 corresponds to areas where SU2 is partially covered by dust and SU4 is typical of Martian dusty areas. Now we describe the ground morphology of these four spectral units, using high spatial resolution images (Figures 10-14).

\subsubsection{Spectral Unit 1}

[39] Areas spatially correlated to SU1 are located on the dome-shaped formation only. On low- to medium-resolution images, SU1 apparently corresponds to tabular layers composed of a dark material [Glotch and Christensen, 2005]. However, HiRISE and MOC images reveal that this unit 


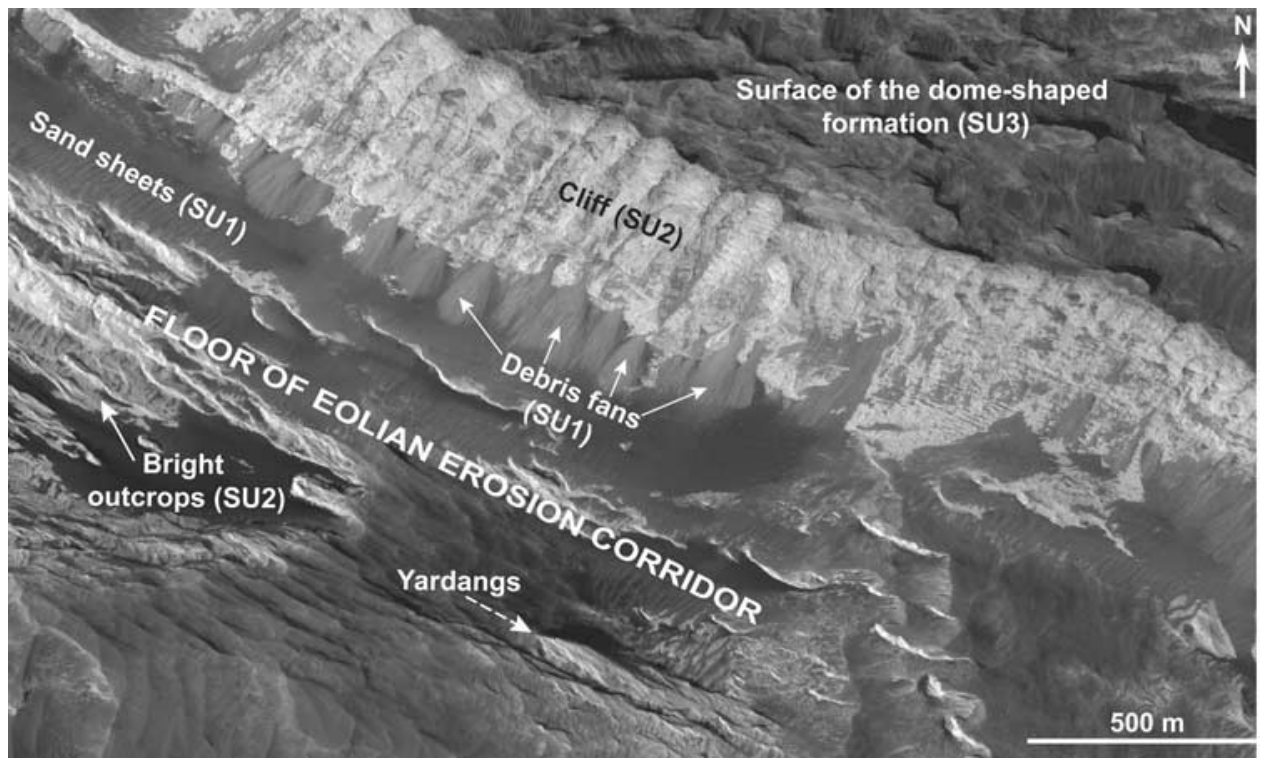

Figure 10. Vertical view of a cliff bordering an eolian erosion corridor, illustrating the distribution of SU1, SU2, and SU3 with respect to the dome-shaped, layered formation (HiRISE image 003406_1830, location indicated by a gray box on Figure 1).

rather corresponds to an extensive cover of dark sand sheets and dunes (Figures 10 and 11) [Catling and Moore, 2003]. These dunes rest on a layered, cohesive, bright material that is hardly visible between the dunes, in the form of outcrops too small to be resolved with OMEGA. Infrared THEMIS images indicate that SU1 is cool at night (darkest surfaces in Aram Chaos, Figure 15c), indicating a relatively low thermal inertia. This is confirmed by the TES thermal inertia value of about $250 \mathrm{~J} \mathrm{~m}^{-2} \mathrm{~K}^{-1} \mathrm{~s}^{-1 / 2}$ measured on this unit
[Putzig and Mellon, 2007]. This value is consistent with unconsolidated sand dunes with a particle size around 400-460 $\mu \mathrm{m}$ [Presley and Christensen, 1997]. In conclusion, SU1 corresponds to extensive superficial sand sheets and dunes enriched in ferric oxides, which cover some parts of the dome-shaped formation.

\subsubsection{Spectral Unit 2}

[40] Areas spatially correlated to SU2 are located within the dome-shaped formation. They are composed of dark,

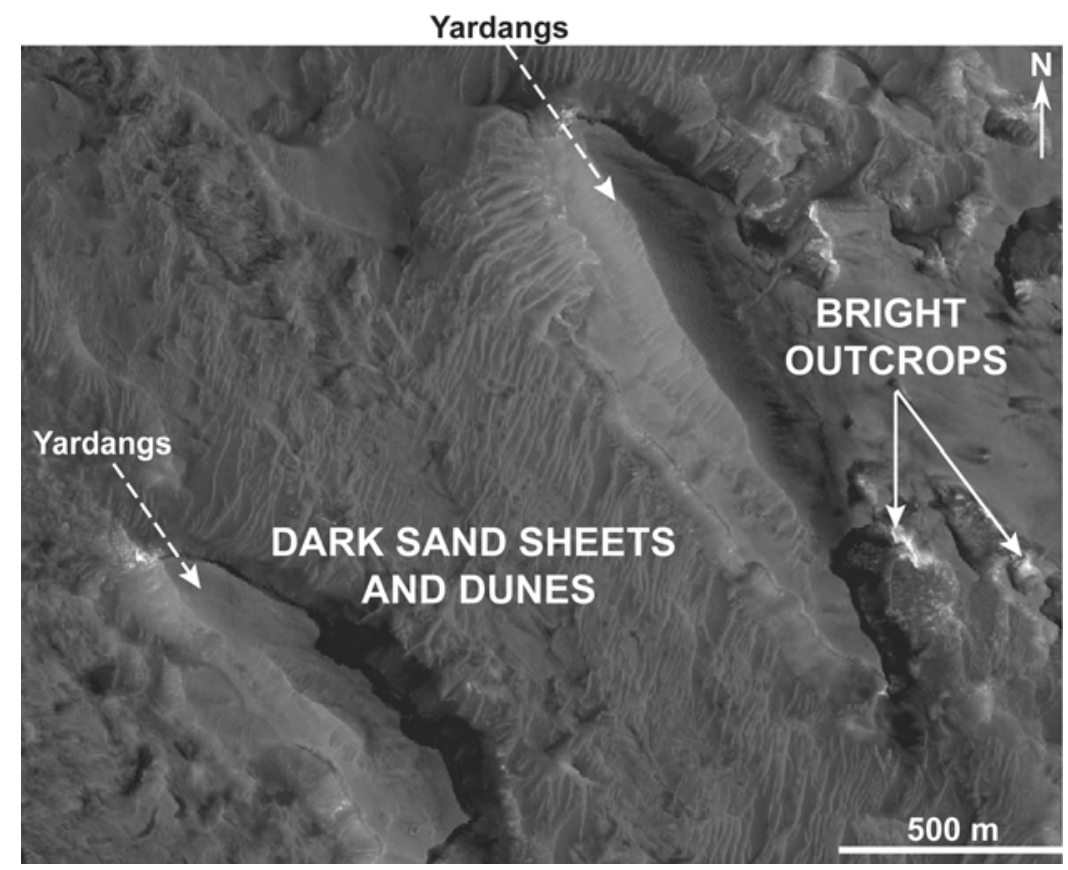

Figure 11. Typical landscape corresponding to SU1. Dark sand sheets and dunes almost completely cover a layered bright material visible in a few scattered outcrops. Winds blowing from the NW have sculpted yardangs in this bright material (HiRISE image 003406_1830, location indicated by a gray box in Figure 1). 


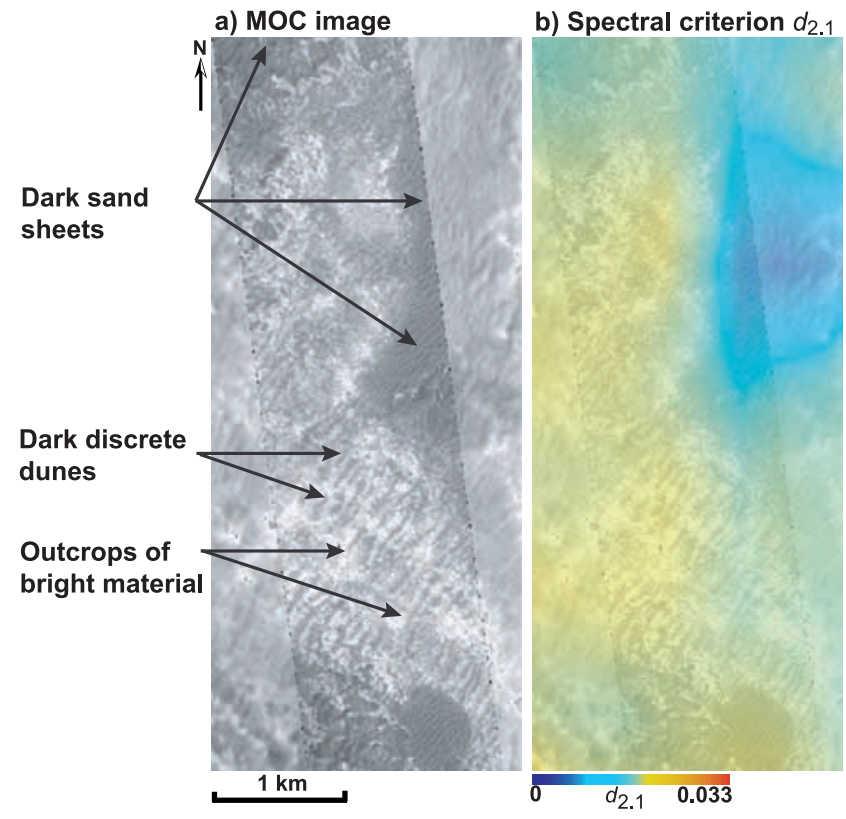

Figure 12. (a) Typical landscape corresponding to SU2 (MOC image M08-06231): alternation of dark sand sheets, dark discrete dunes, and intervening outcrops of a bright material. (b) Value of the $2.1 \mu \mathrm{m}$ spectral criterion superimposed on the same MOC image.

discrete, scattered dunes similar to those of SU1, alternating with wide outcrops of a bright, layered material (Figures 10 and 12a). By comparison with SU1, the spectral signatures of ferric oxides in this unit may be attributed to the dunes. The bright outcrops are similar to those observed between

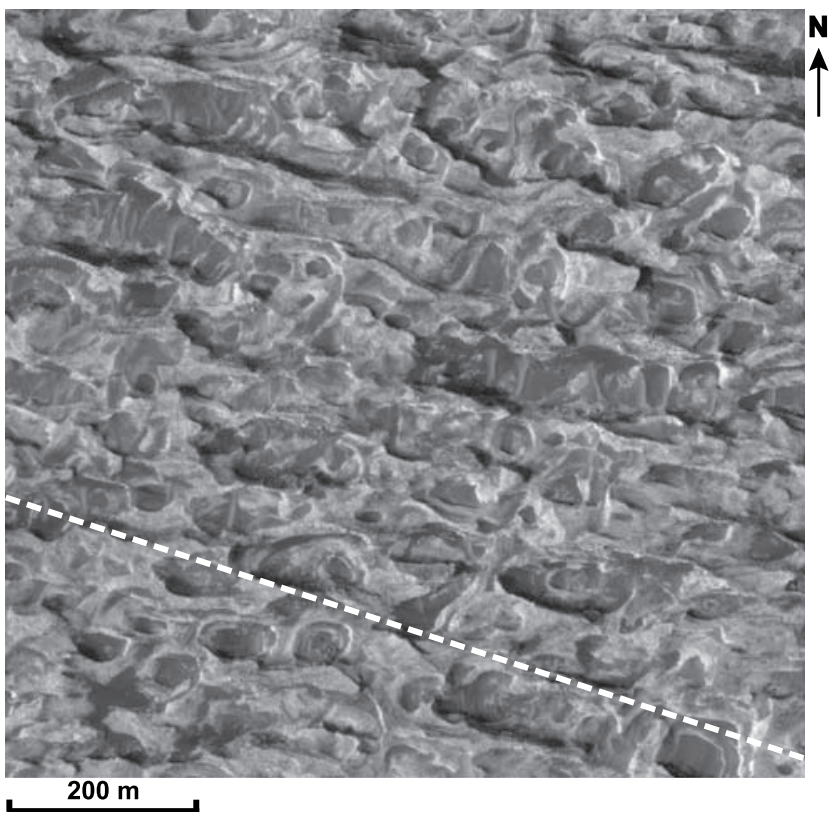

Figure 13. Typical landscape corresponding to SU3 (HiRISE image 003406 1830, location indicated by a gray box in Figure 1). A bright material sculpted in ridges and furrows striking WNW-ESE is more or less covered by dark dust. The dotted line indicates the direction of the ridges and furrows.
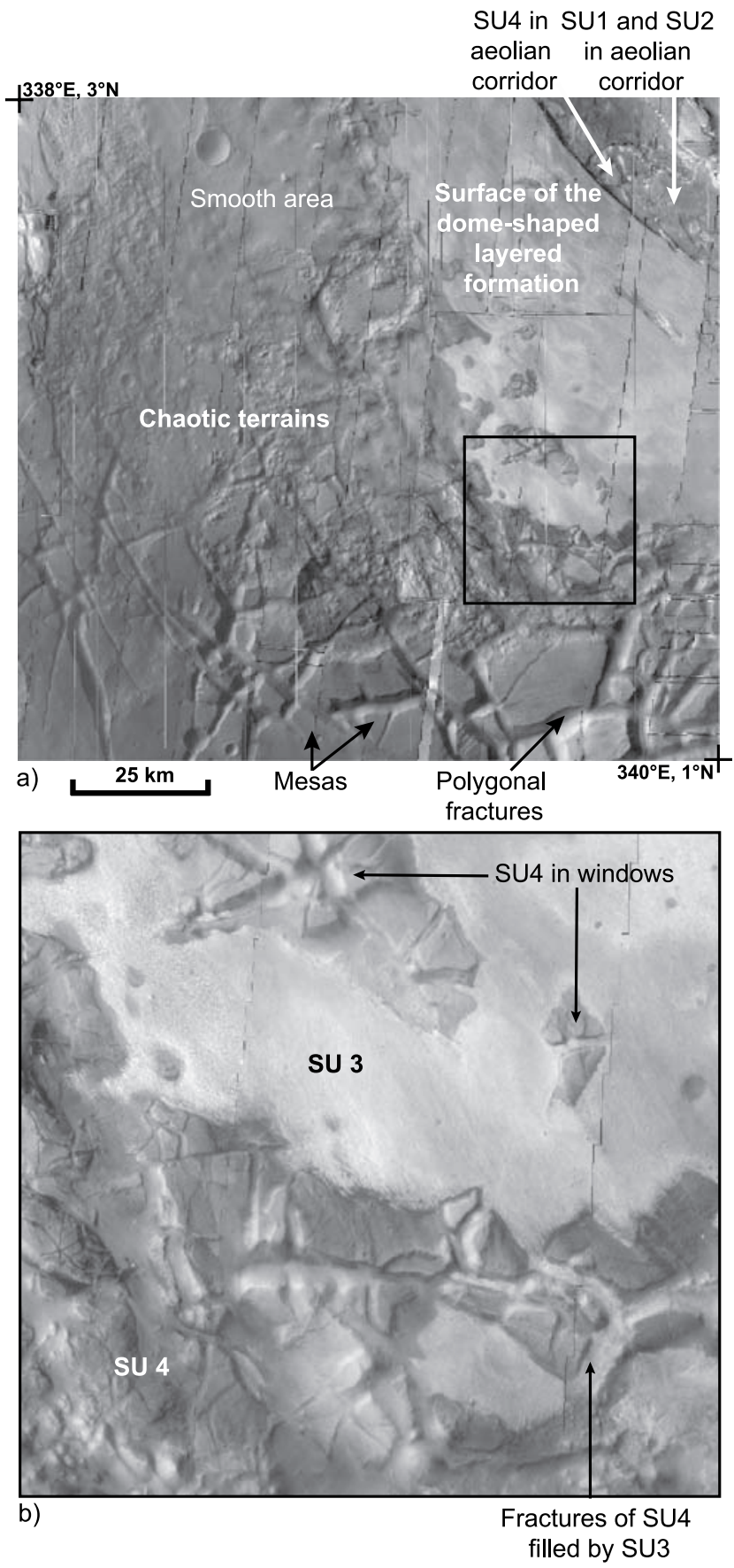

Figure 14. (a) Typical landscape corresponding to SU4. View of the chaotic terrains structure with a visible THEMIS mosaic (location indicated by a gray box in Figure 1). (b) Close-up view of the contact between these terrains and the dome-shaped, layered formation.

the dunes of SU1 but, in this case, these outcrops are large enough to be resolved by OMEGA. The $2.1 \mu \mathrm{m}$ absorption band, which is typical of monohydrated sulfates, is particularly deep on these outcrops (Figure 12b). Nighttime infrared THEMIS images indicate a warmer surface for these outcrops (brighter areas, indicating a higher thermal inertia) than the dark dunes of SU1 (Figure 15c). The TESderived thermal inertia value is around $350 \mathrm{~J} \mathrm{~m}^{-2} \mathrm{~K}^{-1} \mathrm{~s}^{-1 / 2}$ for this unit [Putzig and Mellon, 2007]. Therefore, this 


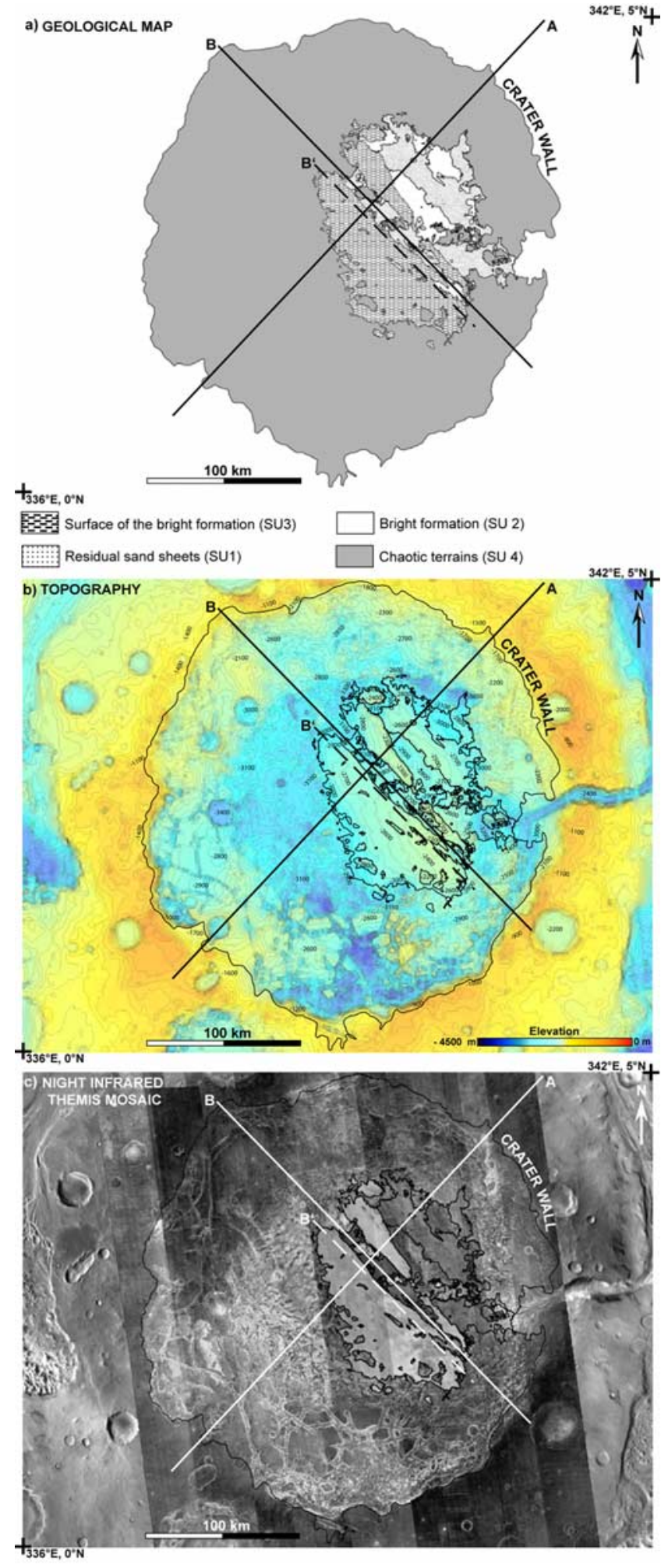

Figure 15. (a) Map of the four spectral units identified in Aram Chaos. (b) Topographic map extracted from MOLA DEM (interval of elevation contours is $100 \mathrm{~m}$ ). (c) Superimposition of a mosaic of nighttime infrared THEMIS images (darker tones represent cooler surfaces and brighter tones represent warmer surfaces) on a low-resolution visible THEMIS image. Spectral units are contoured in black in Figures $15 \mathrm{~b}$ and $15 \mathrm{c}$. Straight lines indicate locations of cross sections represented in Figure 16. material is probably composed of coarser particles or is more consolidated than SU1.

[41] The bright material of SU2 is sculpted in linear ridges striking NW-SE (Figures 10 and 11). These ridges are similar in shape to terrestrial eolian erosion landforms named yardangs [Breed et al., 1997; Gutiérrez, 2005]. They are wider and steeper at their northwestern tips (Figures 10 and 11). This asymmetry suggests that the ridges were formed by eolian erosion of the bright formation by winds blowing from the NW to the SE.

[42] In conclusion, SU2 corresponds to areas where dark dunes enriched in ferric oxides partially cover a bright, layered material, forming the bulk of the dome-shaped formation and containing monohydrated sulfates.

\subsubsection{Spectral Unit 3}

[43] SU3 corresponds to the surface of the dome-shaped formation. This surface appears smooth on low- to mediumresolution images and on MOLA topographic data. However, at a higher spatial resolution, HiRISE and MOC images reveal that it is composed of convolute ridges and furrows, a few hundred meters in length and striking NNW-SSE. Dust fills the furrows, while a bright material crops out on the ridges (Figures 10 and 13). Erosion cliffs, which cut across the dome-shaped formation, reveal that the bright material constituting the ridges is the same as the one seen between the dunes of SU1 and SU2 (Figure 10). This unit corresponds also to the warmest surface in this region, indicating a relatively high thermal inertia, on nighttime infrared THEMIS images (Figure 15c). The TES-derived thermal inertia varies between 350 and $500 \mathrm{~J} \mathrm{~m}^{-2} \mathrm{~K}^{-1} \mathrm{~s}^{-1 / 2}$ [Putzig and Mellon, 2007]. In conclusion, SU3 corresponds to the sulfate-rich, bright material of SU2 more or less covered by fine-grained particulate deposits.

\subsubsection{Spectral Unit 4}

[44] SU4 is systematically located on chaotic terrains, which are composed of mesas that have been eroded to different degrees and separated from each other by polygonal fractures of various sizes (Figure 14a) [Glotch and Christensen, 2005]. SU4 is present at the top of the mesas, on their slopes and at the bottom of the fractures. This means that the whole area occupied by chaotic terrains is uniformly covered by dust. Hence the mineralogical composition of these terrains cannot be derived from orbital imagery and remains unclear. Nighttime infrared THEMIS images reveal a relatively low thermal inertia, with a TES thermal inertial varying between 230 and $350 \mathrm{~J} \mathrm{~m}^{-2} \mathrm{~K}^{-1} \mathrm{~s}^{-1 / 2}$ [Putzig and Mellon, 2007], on the major part of SU4. This low thermal inertia is probably due to the dust coverage.

\section{Interpretation}

[45] Figures 15 and 16 show an interpretative geological map and a series of cross sections of Aram Chaos derived from the spectral, geomorphological, structural and textural characteristics of the four spectral units identified previously. The map and the cross sections illustrate the following features.

[46] SU4, corresponding to the chaotic terrains, crops out mostly around the dome-shaped formation, which is composed of SU1, SU2, and SU3. Some fractures of the chaotic terrains are filled by materials belonging to SU1, SU2, and SU3 (Figure 14b). Chaotic terrains are also visible in win- 


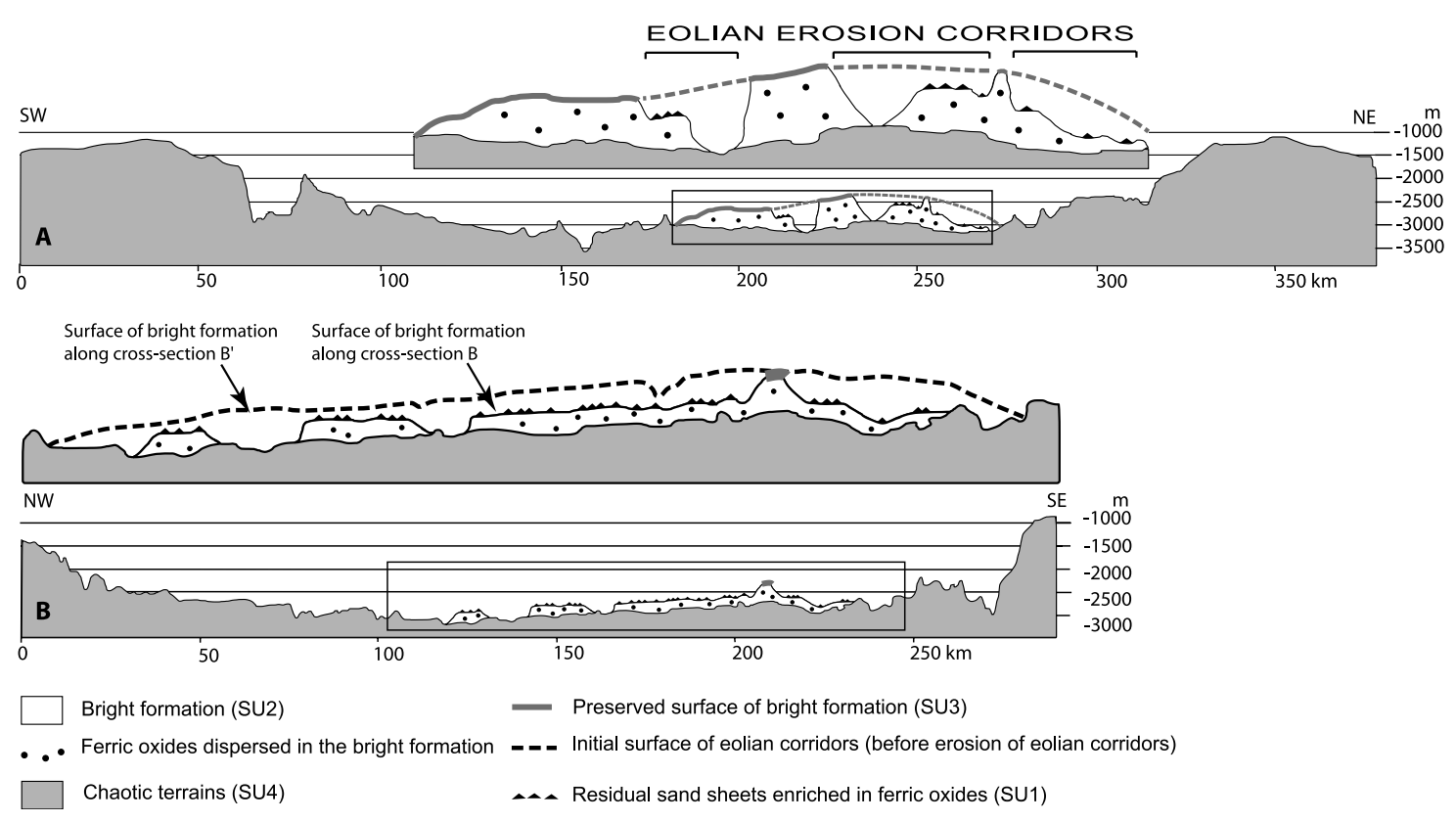

Figure 16. Orthogonal cross sections across Aram Chaos (location on Figure 13), vertical exaggeration is $\times 12.5$.

dows open through the dome-shaped formation (Figure 14). This indicates that the chaotic terrains (SU4) rest stratigraphically below the dome-shaped formation. Therefore, their emplacement and fracturing occurred before the emplacement of the dome-shaped formation.

[47] The dome-shaped formation is approximately circular, with a mean diameter of $125 \mathrm{~km}$ (Figure 15a). Its thickness varies smoothly from $0 \mathrm{~m}$ at the rim to $900 \mathrm{~m}$ in its thickest part. The bulk of this formation is composed of the bright material of SU2, and might therefore correspond to sulfates.

[48] Wide erosion corridors striking NW-SE [Catling and Moore, 2003] have grooved this formation down to various depths (Figures 1, 10, and 16). Yardangs striking NW-SE are visible on their floors (Figures 10 and 11), which suggests that the corridors were formed by erosion of the dome-shaped formation by winds blowing from the NW to the SE. The borders of these corridors are steep linear cliffs, which provide vertical sections across the domeshaped formation (Figure 10). The bright, layered, sulfaterich material of SU2 crops out on the steepest parts of the cliffs. However, because of the relatively low spatial resolution of OMEGA, it is difficult to analyze the exact composition of this material. Therefore, even if the bulk of the dome-shaped, layered formation is constituted of the same material, small variations of composition may exist between the different layers.

[49] The surface of the dome-shaped formation is visible above the cliffs (Figure 10). It is composed of the same bright material as SU2, partially covered by dust (SU3), and extensively sculpted into convolute hectometer-scale ridges and furrows striking WNW-ESE. The shape of these ridges and furrows differs from that of dunes, which develop by eolian mobilization of granular, noncohesive materials like sand [Lancaster, 1995]. It differs also from that of yardangs, which develop by eolian erosion of more consolidated materials [Breed et al., 1997; Gutiérrez, 2005]. On the other hand, the ridges and furrows of SU3 are similar in morphology to sastrugi, which develop by syndepositional or postdepositional eolian mobilization of snow on terrestrial snowdrifts. On Earth, sastrugi have been described only in granular, cohesive but easily erodible materials like snow or mixtures of sand and evaporites [Yasso, 1966; Leonard and Tremblay, 2006]. Hence the presence of these landforms at the surface of the dome-shaped formation suggests that (1) its constituent bright material has been mobilized by WNW-ESE blowing winds during or after its emplacement and (2) that this material is granular and cohesive but easily erodible. The cliffs striking NW-SE crosscut the sastrugilike landforms; this indicates that winds blowing toward the SSE or the NNW mobilized the bright material and formed sastrugi-like landforms on the whole surface of the domeshaped formation during or after its emplacement. Winds blowing from the NW (as indicated by the asymmetric shape of yardangs sculpted in the bright material, Figure 10) carved erosional corridors and cliffs within this formation later.

[50] In the deepest parts of the eolian corridors, the bright material has been completely removed by erosion and the polygonal terrains have been exhumed (Figures 14a and 16). In shallower parts of the corridors, where eolian erosion was less intense, the deepest levels of the bright formation have been preserved, but they are extensively covered by dark sand sheets and dunes enriched in ferric oxides (SU1).

[51] SU1 is systematically located in such erosional corridors grooved through the bright material. It never occurs on the chaotic terrains or at the top of the domeshaped formation. This coverage suggests that the dark sand sheets of SU1 are erosional remnants of the bright material of SU2. This interpretation is confirmed by observations on the cliffs bordering the eolian corridors (Figure 10). These cliffs are partially covered by dark debris fans, which originate from the interior of the bright formation (SU2) and feed the dark sand sheets (SU1). This suggests that 


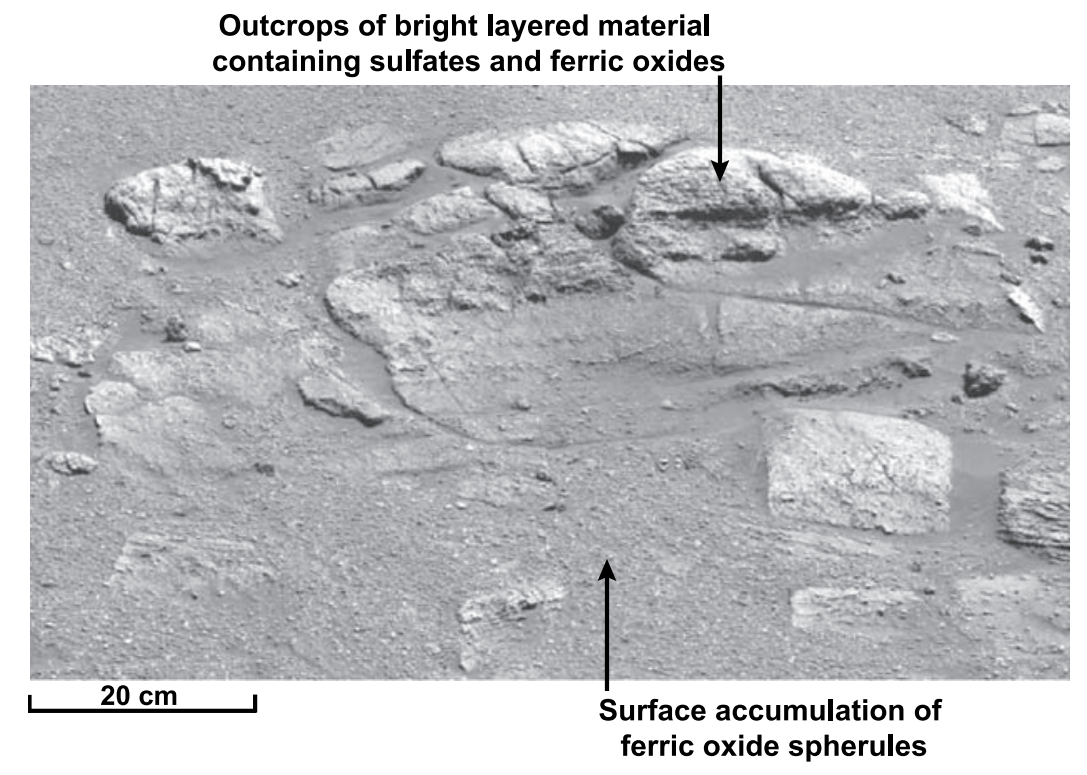

Figure 17. Opportunity's panoramic camera image of Meridiani soil and outcrops ("El Capitain" region) [Bell et al., 2004].

small quantities of ferric oxides are mixed or interstratified with sulfate-rich materials within the bright formation and that they have concentrated in the form of residual debris fans and sand sheets after eolian removal of their sulfaterich matrix. A similar process has been suggested to explain the association of ferric oxides with sulfate-rich materials in other regions of Mars [Bell et al., 2004; Soderblom et al., 2004; Catling et al., 2006; Morris et al., 2006; Farrand et al., 2007; Noe Dobrea et al., 2008; Le Deit et al., 2008].

[52] In conclusion, the bulk of the dome-shaped formation is composed of a layered, bright material enriched in sulfates and ferric oxides (SU2). This material is most probably granular and cohesive though easily erodible. This formation unconformably overlies older and dusty chaotic terrains (SU4). The top of the bright formation (SU3) is partially covered by dust. Eolian removal of the sulfate-rich matrix of the bright material has left residual deposits enriched in ferric oxides (SU1) on the flanking cliffs and on the floor of erosional corridors striking NW-SE.

\section{Discussion}

\subsection{Consistency of the Detected Mineralogy}

[53] The best ferric oxide candidates that we have detected in Aram Chaos are goethite, hematite, ferrihydrite and schwertmannite. Results of previous laboratory experiments provide constraints on whether the presence of these minerals at the surface of Mars is plausible. Chevrier et al. [2006] studied the evolution of a sample of elemental iron that was experimentally weathered in a simulated Martian atmosphere. The first phase to appear after 40 days was siderite. However, this mineral was unstable and turned quickly into goethite through a dissolution-precipitation process involving ferrihydrite as an intermediate phase. Finally, the stable mixture of minerals contained $73.5 \%$ of goethite, $26.5 \%$ of elemental iron and $24 \%$ of ferrihydrite. However, only hematite is thermodynamically stable in the present-day Martian conditions [Chevrier and Mathé, 2007]. Other laboratory experiments indicate that the best analog for Martian hematite results from the heating of goethite [Glotch et al., 2004; Bishop et al., 2006] and that very slow transformation kinetics can explain the persistence of goethite as a metastable phase on Mars [Chevrier and Mathé, 2007]. The occurrence of ferrihydrite as a precursor of other iron oxides such as goethite or hematite, makes it a possible constituent of the Martian surface. Schwertmannite is also a possible precursor for some iron oxides [Bishop et al., 2006; Chevrier and Mathé, 2007]. In conclusion, laboratory experiments suggest that the presence of goethite, hematite, ferrihydrite and schwertmannite at the surface of Mars is chemically plausible, which is in agreement with our analysis of OMEGA data.

[54] With regard to sulfates, the best spectral candidate that we identified in Aram Chaos is kieserite. Laboratory experiments show that the formation of kieserite from the direct dehydration of epsomite and hexahydrite is also plausible on Mars [Freeman et al., 2007]. A more comprehensive analysis of the iron and sulfate components could be derived from the CRISM imaging spectrometer onboard the Mars Reconnaissance Orbiter by observing spectrally pure pixels on outcrops at a scale of $\sim 20 \mathrm{~m}$.

\subsection{Comparison With Ground Mineralogical Analyses in Meridiani Planum}

[55] Meridiani Planum is a wide plain located about $800 \mathrm{~km}$ to the ESE of Aram Chaos. High-resolution HiRISE images show that Meridiani Planum, like Aram Chaos, is composed of dunes that partially cover a bright material. The Opportunity rover, which landed in Meridiani Planum, demonstrated that the bright outcrops are layered and contain both sulfates and ferric oxides in the form of spherules or dispersed in the matrix. Dark surface accumulations of ferric oxide spherules were found in topographic lows close to these outcrops (Figure 17). Erosion and removal of the bright material is believed to be responsible for the release of the spherules and their accumulation at the surface [Bell et al., 2004; Soderblom et al., 2004]. However, these bright outcrops are scattered in a plain that is also 
extensively covered by dust. Therefore, the OMEGA spectral signatures in Meridiani Planum are less intense, and the signature of sulfates is hardly visible in Meridiani Planum [Arvidson et al., 2006].

[56] Spectral analyses of the formations discovered in Meridiani Planum were performed by three instruments onboard the Opportunity rover (MiniTES, Pancam and Mössbauer). These instruments indicate that the best fit for sulfates contained in the bright outcrops is provided by $\mathrm{Mg}$ and $\mathrm{Ca}$ sulfates [Christensen et al., 2004b; Clark et al., 2005]. Therefore, the probable detection of kieserite $\left(\mathrm{MgSO}_{4}-\mathrm{H}_{2} \mathrm{O}\right)$ in the bright formation of Aram Chaos is consistent with ground observations in Meridiani Planum. The spherules of ferric oxides have been interpreted as concretions of crystalline hematite [Squyres et al., 2003; Christensen et al., 2004b; Klingelhöfer et al., 2004]. Goethite, ferrihydrite or schwertmannite can also explain the spectra of some outcrops and soils in Meridiani Planum [Bell et al., 2004; Farrand et al., 2007]. Therefore the spectral detection of kieserite in the bright material and of iron oxides in the dark surface deposits of Aram Chaos is consistent with mineralogical analyses performed on the ground in Terra Meridiani. This leads us to conclude that these two regions are covered by a similar, bright, layered formation containing both sulfates and ferric oxides. According to Sefton-Nash and Catling [2008], the ferric oxides could have resulted from acid dissolution of ferric sulfates. Later, eolian removal of the sulfate-rich matrix of this formation led to the release and accumulation, in the form of superficial dark deposits, of residual grains enriched in ferric oxides.

\section{Conclusion: Geological History of Aram Chaos}

[57] According to the analysis of the mineralogical composition, structure and morphology of Aram Chaos, we propose the following sequence of events:

[58] 1. The crater floor was covered by a first geological formation, the mineralogical composition of which remains unclear because it is currently masked by dust.

[59] 2. Widespread polygonal fracturing of this formation, possibly triggered by the sudden withdrawal of water stored in minerals [Montgomery and Gillespie, 2005], in ice [Chapman and Tanaka, 2002], or in a subsurface aquifer [Glotch and Christensen, 2005], led to the development of the chaotic terrains.

[60] 3. Later, a layered formation, presently dome shaped, was emplaced unconformably on the chaotic terrains. This younger unit is composed of a bright, granular, cohesive but easily erodible material that contains both sulfates (possibly kieserite or szomolnokite) and ferric oxides (possibly hematite and/or goethite and ferrihydrite and/or schwertmannite). The surface of this formation is partially covered by dust. Various processes may be proposed to explain the emplacement of this formation, including volcanism [Chapman, 2007], lacustrine sedimentary deposition [Glotch and Christensen, 2005] or atmospheric precipitation as in polar layered deposits [Catling et al., 2006]. Surface landforms indicate that the bright material has been mobilized by WNW-ESE blowing winds during or after its deposition.
[61] 4. After its emplacement, winds blowing from the NW grooved large erosion corridors down to various depths through the dome-shaped formation. In these corridors, eolian removal of the sulfate-rich matrix of the bright material has left local accumulations (in the form of debris fans on cliffs and of dark sand sheets and dunes on topographic flats and depressions), of residual grains enriched in iron oxides.

[62] Glotch et al. [2004] and Catling and Moore [2003] interpreted the unit enriched in ferric oxides as a layer interstratified within the dome-shaped formation. Our work shows rather that the bulk of the dome-shaped formation is composed of one single bright material containing sulfates and ferric oxides, and that the unit enriched in ferric oxides corresponds to surface accumulations of residual grains originating from the bright formation. Residual deposits enriched in ferric oxides, overlying a layered formation also enriched in both ferric oxides and sulfates, have also been observed on the ground by the Opportunity rover in Meridiani Planum. This suggests common geological development processes for both localities.

[63] Acknowledgments. This work benefited from financial supports from the Centre National de la Recherche Scientifique, Institut National des Sciences de l'Univers (Programme National de Planétologie), and from the Centre National d'Études Spatiales. M. Massé is supported by a Ph.D. research grant from the French government (Ministère de l'Enseignement Supérieur et de la Recherche). We thank W.H. Farrand and an anonymous reviewer for their insightful comments. Thorough advice from D. Mège, S. Pochat, and A. Bargery greatly improved the quality of this article.

\section{References}

Adams, J. B., M. O. Smith, and P. E. Johnson (1986), Spectral mixture modeling: A new analysis of rock and soil types at the Viking Lander site, J. Geophys. Res., 91, 8098-8112, doi:10.1029/JB091iB08p08098.

Adams, J. B., M. O. Smith, and A. R. Gillespie (1993), Imaging spectroscopy: Interpretation based on spectral mixture analysis, in Remote Geochemical Analysis: Elemental and Mineralogical Composition, edited by C. M. Pieters and P. A. J. Englert, pp. 145-166, Cambridge Univ. Press, New York.

Arvidson, R. E., et al. (2006), Nature and origin of the hematite-bearing plains of Terra Meridiani based on analyses of orbital and Mars Exploration rover data sets, J. Geophys. Res., 111, E12S08, doi:10.1029/2006JE002728.

Bargery, A. S., D. Mège, S. Le Mouélic, and J.-P. Combe (2006), Nearinfrared analysis of Tempe Terra, Olympica Fossae and Nili Fossae from OMEGA data, Lunar Planet. Sci., XXXVII, abstract 1684.

Bell, J. F., III, et al. (2004), Pancam multispectral imaging results from the Opportunity rover at Meridiani planum, Science, 305, 800-806, doi:10.1126/science.1100175.

Bibring, J.-P., et al. (2004), OMEGA: Observatoire pour la Minéralogie, l'Eau, les Glaces et l'Activité, Eur. Space Agency Spec. Publ., 1240, $37-$ 50.

Bibring, J.-P., et al. (2007), Coupled ferric oxides and sulfates on the Martian surface, Science, 317, 1206-1210, doi:10.1126/science.1144174. Bishop, J. L., M. D. Dyar, M. Parene, A. Drief, R. L. Mancinelli, M. D. Lane, and E. Murad (2006), Understanding surface processes on Mars through study of iron oxides/oxyhydroxides: Clues to surface alteration and aqueous processes, Lunar Planet. Sci., XXXVII, abstract 1438.

Boardman, J. W. (1989), Inversion of imaging spectrometry data using singular value decomposition, paper presented at 12th Canadian Symposium on Remote Sensing, Inst. of Electr. and Electr. Eng., Vancouver, B. C., Canada.

Breed, C. S., J. F. McCauley, M. I. Whitney, V. P. Tchakerian, and J. E. Laity (1997), Wind erosion in drylands, in Arid Zone Geomorphology: Process, Form and Change in Drylands, 2nd ed., edited by D. S. G. Thomas, pp. 437-464, John Wiley, Chichester, U. K.

Catling, D. C., and J. M. Moore (2003), The nature of coarse-grained crystalline hematite and its implications for the early environment of Mars, Icarus, 165, 277-300, doi:10.1016/S0019-1035(03)00173-8.

Catling, D. C., S. E. Wood, C. Leovy, D. R. Montgomery, H. M. Greenberg, C. R. Glein, and J. M. Moore (2006), Light-toned layered deposits in Juventae Chasma, Mars, Icarus, 181, 26-51, doi:10.1016/j.icarus.2005.10.020. 
Chapman, M. (2007), The Geology of Mars: Evidence From Earth-Based Analogs, Cambridge Univ. Press, New York.

Chapman, M. G., and K. L. Tanaka (2002), Related magma-ice interactions: Possible origins of chasmata, chaos, and surface materials in Xanthe, Margaritifer, and Meridiani Terrae, Mars, Icarus, 155, 324-339, doi:10.1006/icar.2001.6735

Chevrier, V., and P. E. Mathé (2007), Mineralogy and evolution of the surface of Mars: A review, Planet. Space Sci., 55, 289-314, doi:10.1016 j.pss.2006.05.039.

Chevrier, V., R. Roy, S. Le Mouélic, D. Borschneck, P. E. Mathé, and P. Rochette (2006), Spectral characterization of weathering products of elemental iron in a Martian atmosphere: Implications for Mars hyperspectral studies, Planet. Space Sci., 54, 1034-1045, doi:10.1016/j.pss.2005.12.019.

Christensen, P. R., R. V. Morris, M. D. Lane, J. L. Bandfield, and M. C. Malin (2001), Global mapping of Martian hematite mineral deposits: Remnants if water-driven processes on early Mars, J. Geophys. Res. 106(E10), 23,873-23,885, doi:10.1029/2000JE001415.

Christensen, P. R., et al. (2004a), The Thermal Emission Imaging System (THEMIS) for the Mars 2001 Odyssey mission, Space Sci. Rev., 110 $85-130$.

Christensen, P. R., et al. (2004b), Mineralogy at Meridiani Planum from the Mini-Tes experiment on the Opportunity rover, Science, 306, 1733 1739.

Clark, B. C., et al. (2005), Chemistry and mineralogy of outcrops at Meridiani Planum, Earth Planet. Sci. Lett., 240, 73-94, doi:10.1016/ j.eps1.2005.09.040.

Combe, J.-P., et al. (2008), Analysis of OMEGA/Mars Express hyperspectral data using a Multiple-Endmember Linear Spectral Unmixing Model (MELSUM): Methodology and first results, Planet. Space Sci., 56, 951 975, doi:10.1016/j.pss.2007.12.007.

Crowley, J. K., D. E. Williams, J. M. Hammarstrom, N. Piatak, I.-M. Chou, and J. C. Mars (2003), Spectral reflectance properties $(0.4-2.5 \mu \mathrm{m})$ of secondary Fe-oxide, Fe-hydroxide, and Fe-sulphate-hydrate minerals associated with sulphide-bearing mine wastes, Geochem. Explor. Environ. Anal., 3, 219-228, doi:10.1144/1467-7873/03-001.

Farrand, W. H., et al. (2007), Visible and near-infrared multispectral analysis of rocks at Meridiani Planum, Mars, by the Mars Exploration Rover Opportunity, J. Geophys. Res., 112, E06S02, doi:10.1029/2006JE002773.

Fergason, R. L., P. R. Christensen, and H. H. Kieffer (2006), High-resolution thermal inertia derived from the Thermal Emission Imaging System (THEMIS): Thermal model and applications, J. Geophys. Res., 111, E12004, doi:10.1029/2006JE002735.

Freeman, J. J., A. Wang, and B. L. Jolliff (2007), Pathways to form kieserite from epsomite at mid to low temperatures, with relevance to Mars, Lunar Planet. Sci., XXXVIII, abstract 1298.

Gendrin, A., et al. (2005), Sulfates in Martian layered terrains: The OMEGA/ Mars Express view, Science, 307, 1587-1591, doi:10.1126/science. 1109087

Glotch, T. D., and P. R. Christensen (2005), Geologic and mineralogic mapping of Aram Chaos: Evidence for a water-rich history, J. Geophys. Res., 110, E09006, doi:10.1029/2004JE002389.

Glotch, T. D., R. V. Morris, P. R. Christensen, and T. G. Sharp (2004), Effect of precursor mineralogy on the thermal infrared emission spectra of hematite: Application to Martian hematite mineralization, J. Geophys Res., 109, E07003, doi:10.1029/2003JE002224.

Gutiérrez, M. (2005), Climatic Geomorphology, Developments in Earth Surface Processes 8, 760 pp., Elsevier, New York.

Klingelhöfer, G., et al. (2004), Jarosite and hematite at Meridiani Planum from Opportunity's Mössbauer spectrometer, Science, 306, 1740-1745.

Kraal, E., M. Kleinhans, T. Zegers, J. Oosthoek, A. Rossi (2006), Studying the connection between Aram Chaos and Ares Vallis, paper presented at European Planetary Science Congress 2006, Eur. Planet. Sci. Congr., Berlin, abstract $519 \mathrm{~K}$

Lancaster, N. (1995), Geomorphology of Desert Dunes, 290 pp., Routledge, London.

Langevin, Y., F. Poulet, J.-P. Bibring, B. Schmitt, S. Douté, and B. Gondet (2005), Summer evolution of the North Polar Cap of Mars as observed by OMEGA/Mars Express, Science, 307, 1581-1584, doi:10.1126/ science.1109438.

Le Deit, L., S. Le Mouélic, D. Mège, O. Bourgeois, J.-P. Combe, C. Sotin, A. Gendrin, E. Hauber, N. Mangold, and J.-P. Bibring (2008), Ferric oxides in East Candor Chasma, Valles Marineris (Mars) inferred from analysis of OMEGA/Mars Express data: Identification and geological interpretation, J. Geophys. Res., 113, E07001, doi:10.1029/2007JE002950.

Le Mouélic, S., C. Sotin, J.-P. Combe, A. Gendrin, J. Mustard, J.-P. Bibring, Y. Langevin, B. Gondet, and P. Pinet (2006), Composition of the dust on Mars derived from OMEGA hyperspectral images, Lunar Planet. Sci., XXXVII, abstract 1409.
Leonard, K. C., and B. Tremblay (2006), Depositional origin of snow sastrugi, Eos Trans. $A G U, 87(52)$, Fall Meet. Suppl., Abstract C21C1170

Malin, M. C., G. E. Danielson, A. P. Ingersoll, H. J. Veverka, M. A. Ravine, and T. A. Soulanille (1992), Mars Observer Camera, J. Geophys. Res., 97(E5), 7699-7718.

McEwen, A. S., et al. (2007), Mars Reconnaissance Orbiter's Hig-Resolution Imaging Science Experiment (HiRISE), J. Geophys. Res., 112, E05S02, doi:10.1029/2005JE002605.

Mellon, M. T., B. M. Jakosky, H. H. Kieffer, and P. R. Christensen (2000), High-resolution thermal inertia mapping from the Mars Global Surveyor Thermal Emission Spectrometer, Icarus, 148, 437-455, doi:10.1006/ icar.2000.6503.

Montgomery, D. R., and A. Gillespie (2005), Formation of Martian outlow channels by catastrophic dewatering of evaporite deposits, Geology, 33, 625-628, doi:10.1130/G21270.1.

Morris, R. V., et al. (2006), Mössbauer mineralogy of rock, soil, and dust at Meridiani Planum, Mars: Opportunity's journey across sulfate-rich outcrop, basaltic sand, and dust, and hematite lag deposits, J. Geophys. Res., 111, E12S15, doi:10.1029/2006JE002791.

Noe Dobrea, E. Z., F. Poulet, and M. C. Malin (2008), Correlation between hematite and sulfates in the chaotic terrain east of Valles Marineris, Icarus, 193, 516-534, doi:10.1016/j.icarus.2007.06.029.

Oosthoek, J. H. P., T. E. Zegers, A. Rossi, B. Foing, and G. Neukum (2007), 3-D mapping of Aram Chaos: A record of fracturing and fluid activity, Lunar Planet. Sci., XXXVIII, abstract 1577.

Ormö, J., G. Koratsu, M. A. Chan, B. Beitler, and W. T. Parry (2004), Geological features indicative of processes related to the hematite formation in Meridiani Planum and Aram Chaos, Mars: A comparison with diagenetic hematite deposits in southern Utah, USA, Icarus, 171, 295316, doi:10.1016/j.icarus.2004.06.001.

Presley, M. A., and P. R. Christensen (1997), Thermal conductivity measurements of particulate materials: 2. Results, J. Geophys. Res., 102, 6551-6566, doi:10.1029/96JE03303

Putzig, N. E., and M. T. Mellon (2007), Apparent thermal inertia and the surface heterogeneity of Mars, Icarus, 191, 68-94, doi:10.1016/ j.icarus.2007.05.013.

Ramsey, M. S., and P. R. Christensen (1998), Mineral abundance determination: Quantitative deconvolution of thermal emission spectra, J. Geophys. Res., 103(B1), 577-596, doi:10.1029/97JB02784

Rencz, A. N. (1999), Manual of Remote Sensing: Remote Sensing for the Earth Science, 3rd ed., 707 pp., John Wiley, Hoboken, N. J.

Roberts, D. A., M. Gardner, R. Church, S. Ustin, G. Scheer, and R. O. Green (1998), Mapping chaparral in the Santa Monica Mountains using multiple endmember spectral mixture models, Remote Sens. Environ., 65(3), 267-279.

Schultz, P. H., J. L. Rogers, and R. A. Schulz (1982), Impact-basin control of channels and valleys on Mars, Lunar Planet. Sci., XIII, 700-701.

Sefton-Nash, E., and D. C. Catling (2008), Hematitic concretions at Meridiani Planum, Mars: Their growth timescale and possible relationship with iron sulfates, Earth Planet. Sci. Lett., 269, 366-376, doi:10.1016/ j.epsl.2008.02.009.

Sharp, R. P. (1973), Mars: Fretted and chaotic terrains, J. Geophys. Res., 78, 4073-4083, doi:10.1029/JB078i020p04073.

Smith, D. E., et al. (2001), Mars Orbiter Laser Altimeter (MOLA): Experiment summary after the first year of global mapping of Mars, J. Geophys. Res., 106, 23,689-23,722, doi:10.1029/2000JE001364.

Soderblom, L. A., et al. (2004), Soils of Eagle Crater and Meridiani Planum at the Opportunity rover landing site, Science, 306, 1723-1726.

Squyres, S. W., et al. (2003), Athena Mars rover investigation, J. Geophys. Res., 108(E12), 8062, doi:10.1029/2003JE002121.

Tanaka, K. L., and J. A. Skinner Jr. (2004), Advances in reconstructing the geologic history of the Chryse region outflow channels on Mars, Lunar Planet. Sci., XXXV, abstract 1770.

Yasso, W. E. (1966), Heavy mineral concentration and sastrugi-like deflation furrows in a beach salcrete at Rockaway Point, New York, J. Sediment. Petrol., 36(3), 836-838.

J.-P. Bibring, B. Gondet, and Y. Langevin, Institut d'Astrophysique Spatiale, Université Paris XI, Orsay Campus, Bâtiment 121, F-91405 Orsay, France.

O. Bourgeois, L. Le Deit, S. Le Mouélic, and M. Massé, Laboratoire de Planétologie et Géodynamique, Université de Nantes, UMR6112, CNRS, 2 Chemin de la Houssinière, B.P. 92205, F-44322 Nantes CEDEX 3, France. (marion.masse@univ-nantes.fr)

J.-P. Combe, Bear Fight Center, Box 667, Winthrop, WA 98862, USA.

C. Sotin, Jet Propulsion Laboratory, Mail Stop 183-303, 4800 Oak Grove Drive, Pasadena, CA 91109, USA. 